\title{
Article
}

\section{Supply chain resilience: definition, review and theoretical foundations for further study}

Tukamuhabwa, Benjamin R., Stevenson, Mark, Busby, Jerry and Bell, Marta

Available at http://clok.uclan.ac.uk/28021/

Tukamuhabwa, Benjamin R., Stevenson, Mark, Busby, Jerry and Bell, Marta (2015) Supply chain resilience: definition, review and theoretical foundations for further study. International Journal of Production Research, 53 (18). pp. 5592-5623. ISSN 0020-7543

It is advisable to refer to the publisher's version if you intend to cite from the work. http://dx.doi.org/10.1080/00207543.2015.1037934

For more information about UCLan's research in this area go to http://www.uclan.ac.uk/researchgroups/ and search for <name of research Group>.

For information about Research generally at UCLan please go to http://www.uclan.ac.uk/research/

All outputs in CLoK are protected by Intellectual Property Rights law, including Copyright law. Copyright, IPR and Moral Rights for the works on this site are retained by the individual authors and/or other copyright owners. Terms and conditions for use of this material are defined in the policies page.

\section{CLoK}

Central Lancashire online Knowledge www.clok.uclan.ac.uk

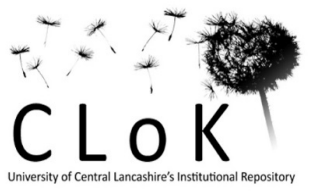




\section{Supply Chain Resilience: Definition, Review and Theoretical Foundations for Further Study}

Benjamin Tukamuhabwa Rwakira, Mark Stevenson ${ }^{1}$, Jerry Busby, and Marta Zorzini

\begin{tabular}{|c|c|}
\hline Name: & Benjamin Tukamuhabwa Rwakira \\
\hline Institution: & Lancaster University \\
\hline \multirow[t]{5}{*}{ Address: } & Department of Management Science \\
\hline & Lancaster University Management School \\
\hline & Lancaster University \\
\hline & LA1 4YX \\
\hline & U.K. \\
\hline E-mail: & b.tukamuhabwarwakira@lancaster.ac.uk \\
\hline Name: & Dr Mark Stevenson \\
\hline Institution: & Lancaster University \\
\hline \multirow[t]{5}{*}{ Address: } & Department of Management Science \\
\hline & Lancaster University Management School \\
\hline & Lancaster University \\
\hline & LA1 4YX \\
\hline & U.K. \\
\hline E-mail: & m.stevenson@lancaster.ac.uk \\
\hline Tel: & 00441524593847 \\
\hline Name: & Dr Jerry Busby \\
\hline Institution: & Lancaster University \\
\hline \multirow[t]{5}{*}{ Address: } & Department of Management Science \\
\hline & Lancaster University Management School \\
\hline & Lancaster University \\
\hline & LA1 4YX \\
\hline & U.K. \\
\hline E-mail: & j.s.busby@lancaster.ac.uk \\
\hline Tel: & 00441524594447 \\
\hline Name: & Dr Marta Zorzini \\
\hline Institution: & Lancaster University \\
\hline \multirow[t]{5}{*}{ Address: } & Department of Management Science \\
\hline & Lancaster University Management School \\
\hline & Lancaster University \\
\hline & LA1 4YX \\
\hline & U.K. \\
\hline Tel: & 00441524593868 \\
\hline E-mail: & m.zorzini@lancaster.ac.uk \\
\hline
\end{tabular}

Keywords: Supply chain resilience; Strategies; Literature review; Complex adaptive systems.

Paper Type: State-of-the-art Review

\footnotetext{
${ }^{1}$ Corresponding Author: m.stevenson@lancaster.ac.uk
} 


\title{
Supply Chain Resilience: Definition, Review and Theoretical Foundations for Further Study
}

\begin{abstract}
There has been considerable academic interest in recent years in Supply Chain Resilience (SCRES). This paper presents a timely review of the available literature on SCRES based on a three-stage systematic search that identified 91 articles/sources. We provide a comprehensive definition of SCRES before strategies proposed for improving resilience are identified and the contributions to the literature are critiqued, e.g. in terms of research method and use of theory. We take stock of the field and identify the most important future research directions. A wide range of strategies for improving resilience are identified, but most attention has been on increasing flexibility, creating redundancy, forming collaborative supply chain relationships and improving supply chain agility. We also find that only limited research has been conducted into choosing and implementing an appropriate set of strategies for improving SCRES. Much of the literature is conceptual, theoretical and normative; the few available empirical studies are mainly cross-sectional and confined to a large firm, developed country context; and, there has been limited use of theory frames to improve understanding. We propose Complex Adaptive Systems (CAS) theory as an appropriate lens for studying SCRES. We demonstrate that SCRES mirrors many characteristics of a CAS including adaptation and co-evolution, nonlinearity, self-organisation and emergence - with implications for the direction of both future research and practice.
\end{abstract}

Keywords: Supply chain resilience; Strategies; Literature review; Complex adaptive systems. 


\section{Introduction}

In recent years, there have been a number of high-profile events and persistent problems that have severely disrupted the ability of firms to produce and distribute their products, including devastating earthquakes, political turmoil, fuel crises, diseases and terrorism (Singhal et al. 2011; Sodhi et al. 2012; Mandal, 2012; Chen et al. 2013; Sawik 2013). Such events have raised awareness among both academics and practitioners of the need to minimise the potentially devastating effects of disruptions by constructing more resilient supply chains. For example, a recent survey by the World Economic Forum (2013) revealed that more than $80 \%$ of companies are concerned about the resilience of their supply chains. Moreover, the idea of facing up to disruptions by building Supply Chain Resilience (SCRES) has recently gained considerable academic support (e.g. Murino et al. 2011; Brandon-Jones et al. 2014; Geng et al. 2014). Building SCRES presupposes that firms can quickly recover from a disruptive event - either returning to normality or progressing to an even better state of operational performance (Shuai et al. 2011; Mandal 2012). Indeed, a firm that responds to a disruption better than its competitors could improve its market position. For example, Craig et al. (2014) conducted an empirical study of Hugo Boss's supply chain and found a significant positive relationship between SCRES and customer demand. It therefore follows that having a resilient supply chain can be important both to short-term survival and to long-term competitiveness.

While some of the disruptions faced by organisations and supply chains are external including natural (e.g. earthquakes) and man-made disasters (e.g. terrorism) - others originate from within the boundaries of the supply chain. Moreover, the effects of some disruptions are exacerbated by the strategies firms deliberately adopt. The implementation of lean initiatives and single-sourcing policies, for example, may help to cut costs and improve coordination, but they may also leave a supply chain with no spare capacity to cater for contingencies and therefore susceptible to disruption (e.g. Tang 2006a; Zhao et al. 2011). Thus, a firm's internal operational decisions may compound its vulnerability to exogenous threats. Furthermore, the growing interdependence of contemporary firms in global supply networks adds to the problem (Finch, 2004; Diabat et al. 2012). Some authors have advised that such interdependency requires firms to ensure that their supply chains are resilient (e.g. Rice \& Caniato 2003; Erol et al. 2010; Carvalho et al. 2012d). Without resilience, a disruption to a single node may culminate in interruptions or reduced capacity for the entire supply chain (e.g. Craighead et al. 2007; Wakolbinger \& Cruz 2011). An example is the Tohoku Earthquake and Tsunami in Japan in 2011. This caused supply chain disruptions not only in 
Japan but also in other countries, including Thailand, Taiwan, Canada, Australia, the United Kingdom and the United States (Reserve Bank of Australia 2011). These disruptions spilled over into the entire global manufacturing supply chain (Brennan 2011); hence, the repercussions were felt all around the world.

The potential impact of disruptions on a firm and its supply chain make a clear case for the importance of building resilience (Carvalho et al. 2012c). For example, it has been reported that supply chain disruptions can cause significant financial and operational losses to firms (e.g. Ponomarov \& Holcomb 2009; Stecke \& Kumar 2009; Ponis \& Koronis 2012). This includes reductions in stock market value, e.g. of 10\% (Hendricks and Singhal 2003), plus falls in operating income, return on sales and return on assets, e.g. of 107\%, 114\% and 93\%, respectively (Hendricks \& Singhal 2005). Further, there are even extreme cases where supply chains have completely collapsed and never recovered from a disruption (Tang 2006b; Xu et al. 2014).

Research specifically on the concept of SCRES can be traced back to the early 2000s when the earliest definitions were coined (e.g. Rice \& Caniato 2003; Christopher \& Peck 2004). Since then, a substantial amount of research has been undertaken using various methodological approaches - such as case studies, surveys, conceptual/theoretical work and modelling - and adopting a limited number of alternative theoretical lenses. However, fundamentally, there remains some confusion and lack of consensus over the definition of SCRES (Spiegler et al. 2012; Mensah \& Merkuryev 2014). While literature reviews can be found in related disciplinary streams, such as supply chain risk management (e.g. Jüttner et al. 2003; Pfohl et al. 2010; Singhal et al. 2011; Ghadge et al. 2012) and supply chain security (e.g. Williams et al. 2008; Gould et al. 2010), a comprehensive review of the SCRES literature is needed to take stock of the field. Although Bhamra et al. (2011) presented a literature review on resilience, their paper provided a broad review of the concept of resilience and considered its application to Small and Medium sized Enterprises (SMEs). The authors did not consider resilience from a supply chain perspective and in fact called for more research that specifically concerns the resilience of supply chains. In response, this paper will review the available literature on SCRES. The objectives specifically are to:

1. Provide a comprehensive definition of SCRES (Section 3);

2. Analyse and classify the available literature on SCRES, identifying gaps and areas in need of further research (Section 4); and 
3. Propose an appropriate theoretical lens for studying SCRES, highlighting its implications for future research and practice (Section 5).

The remainder of this paper is organised as follows. In Section 2, the method used to identify relevant literature is outlined, followed by Section 3, which develops a new, more comprehensive definition of SCRES. Section 4 analyses the strategies proposed in the literature for developing SCRES along with the research methods and theories used in SCRES research. This section also identifies research gaps and suggests potential future research directions for the field. In Section 5, Complex Adaptive Systems (CAS) is suggested and justified as an appropriate theoretical lens for further work on SCRES. Finally, the paper concludes in Section 6.

\section{Methodological Approach}

This study adopts a literature review methodology, which has recently been encouraged in order to advance theory in supply chain management research (Wilding \& Wagner 2014). A systematic procedure for retrieving and selecting the reviewed articles has been applied, following Tranfield et al. (2003) and Denyer \& Tranfield (2009). To minimise bias and improve the validity of findings, the three subsections below outline the approach adopted for sourcing, screening and analysing the articles, as summarised in Figure 1. This includes the criteria involved in sourcing relevant literature and the search strings used, which enhances transparency and aids replication.

\section{[Take in Figure 1]}

\subsection{Step 1 - Sourcing Articles}

OneSearch was used as the main search engine, which enabled us to access a range of major business and management databases, including Emerald, Science Direct, EBSCO Host, ABI/Inform Complete and Web of Science. This access to multiple databases enhances comprehensiveness. We used search strings such as "supply chain resilience", "resilient supply chain", "supply chain resiliency", "supply network resilience”, "resilient supply network" and "supply resiliency" (and substrings of these terms); and we directed our search to "all fields" (i.e. not limiting the search to the title or keywords). Although the search strings were carefully formulated, potentially relevant articles that do not explicitly use any of these terms may not have been identified. We will also not retrieve articles on strategies suitable for building resilience unless a paper specifically frames the strategy in this way. For example, there is a vast literature on flexibility - one of the strategies that we will later 
describe - but we only refer to the subset of articles on flexibility that refer to it as a source of resilience. Our search was however supplemented by Google Scholar to improve completeness. Moreover, to further ensure quality, we focussed exclusively on peer-reviewed journal articles, refereed conference papers and $\mathrm{PhD}$ dissertations. The search was first completed in April, 2013 and repeated again in August, 2014. The search retrieved a total of 235 papers and $5 \mathrm{PhD}$ theses.

\subsection{Step 2 - The Article Screening Process}

The retrieved articles were subjected to three stages of screening:

- First, we cross-checked the articles to ensure duplicate results retrieved from multiple databases were eliminated. This reduced the number of articles from 235 to 178 .

- Second, we checked the relevance of the articles based on their titles and keywords. We aimed to ensure that the focus of an article was on SCRES, e.g. in terms of definitions, strategies, theories or any other aspect. We also scrutinised the abstract and conclusions of each article and, where necessary, scanned the whole article to further assess suitability. After this stage, we retained a total of 74 papers.

- Third, to ensure that we did not miss relevant articles, we further cross-checked the references of the 74 papers and, from this process, retrieved a further fifteen relevant papers. This approach of supplementing the set of papers that had been mechanically retrieved ensured the list of articles was complete, but the number of papers added (15) was not so great to suggest the original search process was inadequate. Three of the five $\mathrm{PhD}$ theses were excluded because their essential results appeared in journal articles. We thus focussed on a total of 91 data sources $(74+15+2)$.

Table 1 identifies the journals where the reviewed articles have been published. It demonstrates the wide range of journals that scholars have used to disseminate their work. Note that the table does not include conference papers and $\mathrm{PhD}$ dissertations: it focuses only on the international peer-reviewed journals where SCRES research has been published.

[Take in Table 1]

\subsection{Step 3 - Analysis and Coding}

Finally, this stage involved extracting and documenting information from each of the 91 sources. To minimise subjectivity, the authors met fortnightly to discuss and resolve inconsistencies. Extracted information included proposed definitions of SCRES, along with 
strategies for building resilience, plus details of the research methods and theoretical lenses applied in prior work.

\section{Defining Supply Chain Resilience (SCRES)}

The specific concept of Supply Chain Resilience (SCRES) has emerged in the literature by drawing on the diverse perspectives of "resilience" that have been developed within the various disciplines to which the broad concept of resilience is relevant. Indeed, several authors have commented on the multidisciplinary and multidimensional nature of resilience (e.g. Ponomarov \& Holcomb 2009; Bhamra et al. 2011; Ponis \& Koronis 2012; Spiegler et al. 2012). The disparate nature of the resilience literature - spread across many fields - and the broad notion of what the concept means has led to authors highlighting the problem of a lack of consensus in the literature on the definition of SCRES (e.g. Spiegler et al. 2012; Mensah \& Merkuryev 2014). The various definitions that can be identified from the articles reviewed here are summarised in Table 2a, while the main elements of these definitions have been extracted and summarised in Table $2 b$.

[Take in Table $2 \mathrm{a} \&$ Table $2 \mathrm{~b}$ ]

Arguably, the two most comprehensive definitions of SCRES are those provided by Ponis \& Koronis (2012) and Ponomarov (2012). For example, these two definitions incorporate the most characteristics in Table $2 \mathrm{~b}$, including adaptive capability and capacity, preparation, response, connectedness and control as well as timely recovery to the original or, preferably, an improved state. However, like all definitions, these two ignore the aspect of cost effectiveness (see final column of Table 2b). Yet the World Economic Forum (2013) indicated that cost efficiency and resilience can coexist without a major negative impact and, ideally, should be complementary. Similarly, Ishfaq (2012) recently argued that SCRES can be achieved without prohibitively high operational costs. Table 3 indicates literature supporting the need to consider cost effectiveness in SCRES. Although formal definitions of SCRES do not appear to incorporate cost effectiveness, this table shows that cost effectiveness has been acknowledged as an important consideration, especially given that scholars have now realised creating SCRES should be compatible with other contemporary practices, including those often looking to drive out operational cost, such as lean (Carvalho et al. 2011b; Cabral et al. 2012; Mensah \& Merkuryev 2014).

[Take in Table 3] 
Although resilient supply chains may not necessarily be those with the lowest costs (Carvalho et al. 2012b; Carvalho et al. 2012c), it is argued here that any definition of the resilience of an economic system without regard for cost is incomplete. Supply chain disruptions should be minimised cost effectively (e.g. Lee 2004; Wagner \& Neshat 2012). Cost efficiency has been identified as a feature of resilient systems (e.g. Fiksel 2003) and the reduction of costs through rapid and effective coordination is a necessary focus of resilient supply chains (Xiao et al. 2012). Moreover, SCRES should not be taken as merely the ability to manage risk, but also the ability to respond to risk in a better and more cost effective way than competitors; and, in the process, gain a competitive advantage (e.g. Hamel \& Valikangas 2003; Yao \& Meurier 2012).

In order to take into account all of the above, we define SCRES as:

The adaptive capability of a supply chain to prepare for and/or respond to disruptions, to make a timely and cost effective recovery, and therefore progress to a postdisruption state of operations - ideally, a better state than prior to the disruption.

\subsection{Operationalisation of Supply Chain Resilience Definition}

The above definition implies that SCRES can be assessed on four aspects - preparation for a disruptive event; response to an event; recovery from the event; and, growth/competitive advantage after the event - while SCRES strategies or capabilities should aim to ensure these aspects are maximised in a timely way and at minimum cost. In addition, the capability to adapt underpins these four aspects. Adaptation means a supply chain has a latent ability to develop different responses to match the nature of the threats it faces. This implies that the supply chain's elements may change to provide an appropriate response to a disruptive event rather than selecting from a pre-existing set of responses. This adaptive capability reflects the nature of disruptive events, which may be unforeseeable, inherent to the supply chain, coevolving with the supply chain's responses, and so on. Over time, the supply chain may learn from disruptive events and corresponding responses; and it may develop new capabilities that make it more resilience to similar threats in the future. As an example, the 1997 fire that destroyed Aisin Seiki's Kariya plant - Toyota's key supplier of P-valves, a critical component to vehicle manufacture - was not anticipated and the responses had not been predetermined. But a quick recovery was enabled by the adaptive capability of the supply network that had been built into strong relationships between the company and its suppliers. This facilitated coordinated and self-organised responses that included setting up alternative p-valve 
production sites at suppliers used to providing other components (Nishiguchi \& Beaudet 1998). If a similar event occurred in the future, the supply chain should be in a better position to respond and the disruption may be less pronounced.

The resilience triangle (Bruneau et al. 2003; Cimellaro et al. 2010; Zobel 2010), which considers factors like the performance level, loss estimation and recovery time, is the most recognised way of assessing a system's resilience. Nevertheless, decision makers in a particular organisation or supply chain may be able to agree on a suitable basis for comparison. Figure 2 presents an adapted version of this to illustrate the four main aspects of our definition of SCRES. Resilience here is depicted as a process whereby a supply chain experiences a series of disruptive events and must make a series of responses and adaptations. Period A in the figure refers to a first disruption, where a large loss is incurred, while Period $\mathrm{B}$ refers to a second disruption where a smaller loss is incurred, perhaps due to the learning experiences and capabilities built through the first disruption. One static measure of resilience would be provided by calculating the area of the shaded shape above the performance curve highlighted in Period A, which makes it possible to evaluate the loss in performance after a disruption and the time it takes to recover. The area considered could also be extended to assess subsequent growth, although a cut-off point has to be established. But a second, more dynamic measure would arguably be provided by comparing the two 'triangles' in Period A and Period B to assess if the supply chain is becoming more resilient over time. Po refers to the normal performance level before the disruption and $\mathrm{Pa}$ is the acceptable minimum performance level below which operations are presumed to shut down. $\mathrm{Pb}$ and $\mathrm{Pw}$ refer to the best and worst outcomes anticipated after recovery. Td is the time when a disruption begins, $\mathrm{Tr}$ is the actual recovery time, and $\mathrm{Ta}$ is the maximum acceptable recovery time. This is a useful approach although it must be acknowledged that measuring SCRES is partly subjective and context specific. For example, what constitutes an acceptable time for recovery (Ta) may be determined by decision makers circumstantially (Cimellaro et al. 2010).

[Take in Figure 2]

\section{Analysis and Categorisation of the Literature}

Much of the available SCRES literature focuses on outlining strategies for improving the resilience of a supply chain to disruption. Therefore, in this section, the SCRES literature is first discussed in terms of the SCRES strategies proposed (Section 4.1). This is followed by a 
discussion of the research methods applied in prior work (Section 4.2) and the theory lenses used (Section 4.3).

\subsection{Key Strategies for Building Supply Chain Resilience}

In Table 4, twenty four different strategies for achieving SCRES are summarised together with relevant authors, e.g. who have identified, referred to, or investigated the particular strategy. The strategies have been broadly organised into two categories - proactive and reactive strategies - although some particular strategies can be either proactive or reactive depending on when and why they are applied. For example, collaboration can help to mitigate disruptions before they occur, e.g. by facilitating information sharing and the use of other strategies, like building security and supplier development. But it can also be used to aid recovery after a disruption by enabling supply chain actors to share resources and provide a coordinated response (Nishiguchi \& Beaudet 1998; Scholten et al. 2014). Also, some of the strategies in the table are interrelated while others reinforce each other. For example, building social capital and relational competences can be regarded as facilitators of collaboration. Visibility and velocity can support agility (Christopher \& Peck 2004) while the use of information technology seems indispensable for most of the strategies. It is also noticeable from the table that more proactive than reactive strategies are highlighted in the literature. On the one hand, these strategies may be preferred in practice as they can be applied to prepare for a disruption rather than to respond. Thus, they are likely to support the continuation of 'operations as normal' and minimise vulnerability. On the other hand, managers may be reluctant to implement proactive strategies since it becomes difficult to justify investments that mitigate potential disruptive events which may not ultimately occur. Finally, although we have classified the strategies here as proactive and/or reactive, it is acknowledged that there is a grey area. Although we have categorised the strategies according to when they are applied in accordance with other scholars (e.g. Ghadge et al. 2012; Saenz \& Revilla 2014) - some strategies may be planned and crafted before a disruption but only applied after the disruption. For example, redundant suppliers may be selected before the risk event but only contracted afterwards. Thus, it may be valuable for future research to develop a more elaborate categorisation of SCRES strategies.

[Take in Table 4]

Table 4 reveals that the most commonly cited SCRES strategies involve increasing flexibility, creating redundancy, forming collaborative supply chain relationships and 
improving supply chain agility. This is consistent with previous researchers who have considered these strategies as the most critical for SCRES (e.g. Longo \& Oren 2008; Jüttner \& Maklan 2011; Ponis \& Koronis 2012). These four key strategies - some of which are interrelated - are briefly discussed below before a broader discussion and assessment of resilience strategies follows.

\subsubsection{Flexibility}

Erol et al. (2010) defined flexibility as the ability of an enterprise to adapt to the changing requirements of its environment and stakeholders with minimum time and effort. Literature reveals various flexibility practices that can enhance SCRES, such as postponement, a flexible supply base, flexible transportation, flexible labour arrangements, and order fulfilment flexibility (e.g. Tang 2006b; Christopher and Holweg 2011; Pettit et al. 2013). For example, it is argued that flexibility through postponement enhances resilience during a crisis by deferring demand to a future period (Tang 2006b). Thus, flexibility creates SCRES by enhancing prompt adaptability during turbulence (e.g. Christopher \& Holweg 2011). It also aids a supply chain's rapid response and recovery, and this can be facilitated by the availability of alternative choices (redundancy), including alternative suppliers (e.g. Sheffi \& Rice 2005). Flexibility also enables resources to be more easily redeployed, including transportation and labour resources (Pettit et al. 2013). Flexibility may apply both to a firm and to the supply chain (Stevenson \& Spring 2007). Recent work has examined how Extreme Value theory can be used to price the value of flexibility when threatened with disruption, including the value of dual sourcing (Bicer 2015); and this may be a promising line of further study.

\subsubsection{Creating Redundancy}

Redundancy involves the strategic and selective use of spare capacity and inventory that can be invoked during a crisis to cope, e.g. with supply shortages or demand surges (Christopher \& Peck 2004). Creating redundancy can be an expensive means of building resilience. For example, spare capacity is needed along the critical path to reduce potential vulnerability and build resilience (Christopher \& Rutherford 2004). It is however important to note that certain factors like geographical location and the total (global) demand should be considered when relying on redundancy to build SCRES. For example, if redundant suppliers are in close proximity to the disrupted supply network, they may also be affected by the event (such as in the case of an earthquake or flood). Meanwhile, assuming, for example, that there are three suppliers located in different continents each with a capacity of 60 units, including 10 units of 
excess capacity, then the total global capacity will be 180 units. Also assuming the total (global) demand is 150 units and one of the suppliers encounters a major disruption leading to closure, the global capacity will reduce to 120 units, which will not handle the global demand of 150 units. This example also demonstrates how global systems are interlinked and therefore how it becomes inappropriate to isolate the supply chain from other global systems because adaptation pressures or threats in such systems can also have a bearing on the supply chain's resilience.

Further, it is also asserted that redundancy involves the duplication of capacity in order to continue operations during a failure (Rice \& Caniato 2003), and that it can therefore also be considered a route to flexibility (e.g. Jüttner \& Maklan 2011; Kristianto et al. 2014). Indeed, Johnson et al. (2013) found that redundancy increases flexibility, which facilitates response through the adaptable deployment of resources. This helps to avoid delay, thereby increasing SCRES. Although building flexibility is closely linked to redundancy, flexibility can also be achieved in other ways, e.g. by employing a multi-skilled labour force, installing multipurpose machines, and creating flexible contractual arrangements. Such flexibilities that do not necessarily rely on redundancy have been preferred by various scholars because they save resources (e.g. Christopher \& Holweg 2011; Thun et al. 2011).

\subsubsection{Supply Chain Collaboration}

According to Pettit et al. (2013), supply chain collaboration refers to the ability to work effectively with other entities for mutual benefit in areas such as forecasting, postponement and risk sharing. Collaboration could also involve information exchange, which can reduce uncertainty, increase transparency and facilitate the creation and sharing of knowledge, such as about supply chain risks and uncertainties (Christopher \& Peck 2004). Collaboration can also enable supply chain partners to share the costs of building security and resilience (Bakshi $\&$ Kleindorfer 2009). Moreover, it influences the processes adopted by supply chain partners to ensure supply chain recovery (Ghadge et al. 2012). For example, collaboration can facilitate the sharing of resources and other complementary skills necessary for recovery from a disruption (Scholten et al. 2014). Collaboration also enhances SCRES by enabling supply chain partners to support each other during a disruptive event (Jüttner \& Maklan 2011) and to provide a flexible and coordinated response. For example, Toyota's collaboration with suppliers following the 1997 Aisin Seiki Kariya plant fire referred to earlier in Section 3.1 (Nishiguchi \& Beaudet 1998). This example is also useful in reminding us how certain practices in supply chain relationships, like just-in-time supply and single-sourcing supply 
partnerships create vulnerabilities that must be traded off against the benefits of these practices, like strong networks that could potentially facilitate a rapid response to a crisis.

\subsubsection{Supply Chain Agility}

Christopher \& Peck (2004) defined supply chain agility as the ability to respond quickly to unpredictable changes in demand or supply; this could perhaps be achieved through a rapid change to business processes and systems (Erol et al. 2010). Christopher \& Peck (2004) suggested that supply chain agility is mainly composed of visibility and velocity. Supply chain visibility refers to the ability to see through the entire supply chain (Christopher \& Peck 2004). It enables a clear view of the whole chain, which may help in detecting signals of impending disruptions. Visibility implies having knowledge of the status of a supply chain's assets and environment (Pettit et al. 2013), thereby also helping to avoid overreactions, unnecessary interventions and ineffective decisions in circumstances of risk (Christopher \& Lee 2004). Furthermore, it helps the supply chain to effectively respond to and recover from disruptions through, for example, identifying vulnerable suppliers, thereby allowing enough time to develop countermeasures against potential failures (Jüttner \& Maklan 2011). For example, Procter \& Gamble planners have tried to strengthen their supply chain visibility by installing monitoring tools to map the supply chain so as to improve threat awareness and receive timely warnings of potential disruptions (Saenz \& Revilla 2014). Saenz \& Revilla (2014) further describe how supply chain visibility helped Cisco to improve its agility and resilience to the Japanese earthquake and tsunami of 2011. Within twelve hours of the disaster, Cisco was able to map out its supply base beyond tier one suppliers (more than 300 suppliers) and within twenty-four hours, it was able to trace its customers and field 118 customer enquiries. This helped it to build a firm SCRES agenda and survive the effects of the disaster (Saenz \& Revilla 2014). The second element of agility referred to by Christopher \& Peck (2004) - supply chain velocity - focuses on the pace of flexible adaptations (Stevenson \& Spring 2007), and thus determines the recovery speed of the supply chain from a risk event (Jüttner \& Maklan 2011).

\subsubsection{An Assessment of Research on SCRES Strategies}

The four core strategies discussed above have received the majority of the attention in the SCRES literature. Beyond these four strategies, the literature on means of developing resilience to supply chain threats or disruptions is broad but limited in depth (see Table 4). Moreover, although the SCRES literature has identified many strategies for creating SCRES, few studies have gone beyond this to focus on how firms can actually develop or implement 
these strategies (Blackhurst et al. 2011). Yet, SCRES research should not only be about identifying strategies, but also about understanding how they can be successfully implemented. For example, it is abundantly clear that SCRES strategies have financial implications that may limit their implementation. Other issues, such as corruption, sociopolitical instability, and unethical competitive practices, which are common sources of business risks (Lakovou et al. 2007), may also pose a threat to a SCRES strategy implementation. Similarly, how firms can choose between different SCRES strategies is under-researched. Given that a firm has limited resources to deploy, what factors should a manager take into consideration when deciding how to improve SCRES? One of the factors influencing the choice of strategy to adopt is likely to be a firm's or individual's perceptions of risk (Martin et al. 2009; Park 2011). Thus, perceptions of supply chain risks and how such perceptions shape decisions concerning the choice of certain SCRES strategies over others could be an important consideration for future research.

The SCRES research literature has also not tended to focus on particular threats or to develop strategies that build resilience towards threats individually. Scholars have, however, claimed that in order to develop appropriate supply chain risk management approaches, risks should be segmented and categorised in some way (e.g. Habermann 2009; Schlegel \& Trent 2012). Hence, strategies might be adopted to deal with categories of threats. Categories may relate, for example, to disruptions caused by intentional actions or physical events, to threats that are endogenous or exogenous to the supply chain, and so on. These categories may then require different treatments or specific resilience strategies. For example, adaptive threats such as posed by product counterfeiting, terrorism and other criminal acts are perpetrated by rational actors who also undertake research and change, and who craft new counter-strategies to evade detection (Spink 2011). The strategy implemented to deal with this type of threat would therefore most likely have to take on similarly adaptive characteristics. Indeed, Pettit et al. (2010) contended that the desired level of resilience is achieved when there is a match between vulnerabilities and corresponding capabilities. But it is not well known how broadly applicable some SCRES strategies are, i.e. whether they are suitable for dealing with a wide range of threats. If so, it may be these that are favoured by managers in practice. But it may be, for example, that some strategies increase resilience to one threat but increase susceptibility or vulnerability to another - this phenomenon is explored further below.

From the literature, there are varying views on the exact relationship between constructs such as flexibility, redundancy, collaboration and agility (e.g. Tang \&Tomlin 2008; Zsidisin \& Wagner 2010; Jüttner \& Maklan 2011; Ponis \& Koronis 2012; Johnson et al. 2013). All 
can be considered as antecedents of SCRES (e.g. Zsidisin \& Wagner 2010; Carvalho et al. 2012b; Ponis \& Koronis 2012); however, the fact that they are interrelated is likely to mean that there are both synergies and trade-offs among them. Enhancing one may enhance the other. For example, redundancy avails resources needed to facilitate supply chain flexibility and velocity in recovering from disruptions (Jüttner \& Maklan 2011); and flexibility and collaboration may enhance agility (Carvalho et al. 2012b). But conflicts or trade-offs may also be possible; for example, supply chain collaboration may conflict with some forms of supply chain flexibility (e.g. Stevenson \& Spring 2007), collaboration may cause additional threats, e.g. via sharing sensitive information (e.g. Jüttner \& Maklan 2011), and flexibility through multiple sourcing and the opening of many branches by firms may result in liquidity risk (e.g. Jüttner \& Maklan 2011). Avanzi et al. (2013) recently advocated the adoption of real options reasoning to mitigate disruptions arising from supply-demand mismatch risk. The authors explained how risk can be minimised by trading off cost reductions through standardisation against real options that allow a supply chain to benefit from variability through enhanced flexibility, which enables it to respond to latent risk. The study explained how the exploitation of implicit postponement options enabled Maillefer - a Swiss manufacturer - to build SCRES against disruptions caused by economic difficulties and to gain a competitive advantage by creating volatility and later effectively responding to it. It was further indicated that synergies can be created from configuring real options, e.g. postponement, expansion/contraction, switching, and follow on options.

Based on the above discussion, it can be argued that enhancing each SCRES strategy in isolation may be counterproductive, raising the possibility of a moving problem or risk migration (e.g. Grabowski \& Roberts 1997; Alcock \& Busby 2006). In other words, in a bid to achieve one facet of resilience - by enhancing one of its antecedents - we find that other facets are degraded through the effects on other antecedents. This - which is likely to reduce the effectiveness of SCRES strategies - requires a more holistic approach and should be investigated further.

\subsection{Research Methods Applied in the SCRES Literature}

In terms of research method, the dominant approaches in the operations and supply chain management literature are literature reviews or conceptual/theoretical work, case studies, surveys, and modelling work (Seuring \& Müller 2008). A summary of the reviewed SCRES papers based on research method is presented in Figure 2. Note that, in our case, there were no papers in the category of literature review specifically on SCRES. From the figure, it is 
clear that the dominant research methods are conceptual/theoretical studies and modelling work.

\section{[Take in Figure 3]}

The number of empirical papers - case studies or surveys - is limited to just nineteen articles, as summarised in Table 5. These articles are predominantly cross-sectional studies focusing, for example, on the strategies a supply chain may use or has previously used. Only two of these studies are longitudinal, which would allow for observing how a supply chain responds, adapts, or recovers over time. Moreover, most of the empirical studies have been conducted in developed countries, notably in the European Union and the USA. Further, the emphasis of these studies has been on large manufacturing firms, and not on specific categories of risks, with the exceptions being Rice \& Caniato (2003), Jüttner \& Maklan (2011) and Johnson et al. (2013), who focused on risk and disruption in the context of terrorism, global financial crisis and a rail crash, respectively. The papers that can be categorised as either conceptual/theoretical contributions or as being modelling work are listed in Table 6.

[Take in Table 5 and Table 6]

\subsubsection{An Assessment of the Methodologies Applied in SCRES Research}

The lack of empirical work on SCRES presents a distinct knowledge gap. It means that we cannot clearly understand how SCRES can be either achieved or, indeed, lost in practice. What is proposed in theory may not apply in practice. Also, the few available empirical papers are either case or survey based only, with cases being typically cross-sectional and surveys typically being based on a single respondent from each firm. Heavy reliance on surveys, for example, means that our understanding is limited to what people in organisations are willing to describe. This is, in itself, a limitation because they may have an imperfect understanding of their supply chains. They may also have limited knowledge of the ramifications of disruptive influences and, thus, may be unwilling or unable to describe the strategies they believe give them a potential competitive advantage. Also, resilience is interpreted differently by particular groups of people, based on how their interpretation fits their understanding and purpose (Walker et al. 2004). Thus, the distinct lack of other empirical approaches, such as ethnographic work that takes resilience as a social construct, suggests a gap in our understanding of how and why firms construct particular influences as either effective or ineffective, and therefore, how they deal with them as a result. 
Of the papers reviewed, only two - Jüttner \& Maklan (2011) and Boone et al. (2013) adopted a longitudinal approach. The lack of longitudinal studies implies that we cannot fully understand how SCRES evolves over time and, in particular, how a supply chain's capacity for resilience might itself increase or decrease under adaptation pressures, such as cost reduction. For example, in their study of SCRES during a global financial crisis, Jüttner \& Maklan (2011) used a longitudinal design to collect data from three companies both before and after the recession (in 2007 and 2009). This enabled them to understand the status of the three supply chains before the risk event, the effect of the risk event on the supply chains, and the SCRES capabilities (i.e. flexibility, visibility, velocity and collaboration) that helped to avoid or minimise the consequences of the financial crisis in terms of revenue, cost and lead time/availability. SCRES is an adaptive phenomenon that involves change and the corresponding response to that change. It is thus only through longitudinal, as opposed to cross-sectional studies, that researchers can observe change and the corresponding response in practice (Stevenson \& Spring 2007). SCRES is not a one-off event, it should be sustainable, and the processes involved in SCRES, such as adaptation, co-evolution and risk migration, cannot be clearly understood at a single moment in time - they need to be examined over time. They are also arguably difficult to understand by studying a single entity in the supply chain - they need to be examined across multiple related firms in a network. Similarly, unlike a tsunami, some other threats or disruptions to supply chains, like the threat of product counterfeiting, are not discrete events but continuous possibilities.

SCRES research to date has concentrated almost exclusively on the developed world context (see Table 5). Yet, there are grounds for believing that the most catastrophic effects of supply chain failures (particularly on human life) have occurred in developing countries. For instance, the infiltration of counterfeit drugs into the pharmaceutical supply chain has been more prevalent and caused more severe effects in the developing world than in developed countries (Chika et al. 2011). For example, it has been suggested that counterfeit pharmaceuticals led to the death of 2,500 people in 1995 and 192,000 people in 2001 in Nigeria and China, respectively (Chan et al. 2010). Furthermore, developing countries are more vulnerable to particular supply chain threats like political turmoil, including rebel activities and post-election violence, and to bribery, corruption and other unethical business practices (Transparency International 2013). Moreover, the cultural and economic differences that exist between developed and developing economies suggest that perceptions and responses to threats may differ between these contexts. Meanwhile, differences in economic development and the quality of infrastructure, like road and rail networks, may mean certain 
developing countries are more susceptible to certain disruptions than more mature, developed countries. Thus, investigating how SCRES issues are handled in developing countries is an important future research direction.

Literature on SCRES indicates that only limited research has been conducted in SMEs, yet they are major contributors to an economy and constitute a significant part of supply chains. For example, they constitute about 99\% of UK industry (Sullivan-Taylor \& Branicki 2011). Also, SMEs are understood to be more vulnerable to supply chain disruptions than large firms (Thun et al. 2011; World economic Forum report 2012), perhaps because they lack sufficient resources (Finch 2004; Thun et al. 2011) or do not adequately prepare for supply chain disruptions (e.g. Wedawatta et al. 2010). Thus, more research should, for example, be conducted to establish how SMEs try to ensure the resilience of their operations and supply chains amidst their financial and operational constraints.

Finally, much of the available SCRES research has been focussed on manufacturing supply chains. Meanwhile, service supply chains remain under-researched, yet disruptions in service supply chains can be catastrophic to human life. Services such as transport services, banking and finance, insurance, consultancy, telecommunications and healthcare are important to human life, and some also facilitate the manufacturing sector. Hence, more research is required that looks at the resilience of pure service supply chains and of services in manufacturing oriented supply chains.

\subsection{Use of Theory in the SCRES Literature}

This subsection briefly reviews the theories that have been used thus far in SCRES research. Established theoretical lenses help in understanding a phenomenon, in identifying the relationships among variables and in enhancing the generalizability of findings across different contexts (Foy et al. 2011). The notable theories that have been used so far in SCRES research are indicated in Table 7.

\section{[Table in Table 7]}

From Table 7, it is evident that the most commonly used theories are the Resource Based View (RBV), the dynamic capabilities model and systems theory. Overall, the most applied theory is the RBV, which suggests internal organisational resources that are valuable, inimitable, rare and non-substitutable are a source of competitive advantage (Barney 1991). It postulates that a firm is comprised of both the tangible and intangible resources, which, for example, may combine to create capabilities that determine its reaction to several internal and 
external threats as well as to opportunities (Wernerfelt 1984; Barney 1991). In SCRES research, the RBV has been used to explain the resources and capabilities that are considered antecedents of resilience, such as logistics capabilities (Ponomarov \& Holcomb 2009), human, organisational and inter-organisational capital resources (Blackhurst et al. 2011), redundant resources and flexible capabilities (e.g. Park 2011). Other studies (e.g. Ponomarov 2012) have incorporated the related dynamic capabilities perspective, arguing that capabilities for enhancing SCRES should be dynamic to match changes in the environment (e.g. Teece 2007).

Beyond the RBV and the related dynamic capabilities model, authors like Erol et al. (2010) and Blackhurst et al. (2011) have used systems theory to explain resilience as an inherent feature of a system composed of flexibility, agility, adaptive capacity and robustness. A supply chain has been seen as an open system that is vulnerable to disruption from environmental events, with the impact of disruption on such a system depending on its level of resilience (Blackhurst et al. 2011). Through the systems theory lens, Blackhurst et al. (2011) proposed that disruptions to a supply chain due, for example, to stringent security, customs regulations, product complexity or inadequate supplier capacity can reduce SCRES.

Few other theories beyond the above have been used in the SCRES literature. Table 7 refers to seven other theories, but most of these have been used by a single paper only. For example, Parker (2011) used contingency theory, which stipulates that optimal decisions and actions depend on both internal and external factors. This theory considers strategies as necessary responses to the environment (Wagner \& Bode 2008). Applying this theory, Parker (2011) argued that the ability to adopt and implement redundant and flexible SCRES practices depends on perceptions and reactions to current and unexpected risks. Most recently, Day (2014) used complex adaptive systems theory to explain the emergence of resilience in disaster relief supply networks and acknowledged that disaster relief supply networks differ from commercial supply chains.

\subsubsection{An Assessment of the Use of Theory in the SCRES Literature}

Table 7 shows that only 14 SCRES papers (out of 91 papers reviewed) made explicit reference to the use of a theoretical lens. This limited application of theory in SCRES research was also acknowledged by Fang et al. (2012). The lack of theory application may have limited our ability to understand resilience and its related variables as well as the relationships between them. It also makes the generalisation of research findings from one 
context to another difficult. It is therefore important that the SCRES research literature makes greater use of theory to improve our understanding of the phenomenon.

It is argued here that the main theories used so far are not sufficient for explaining SCRES. $\mathrm{RBV}$, for example, which is the most often used theory in the SCRES literature, focuses on a firm's internal resources and does not routinely extend beyond the firm level. Yet, SCRES is a system level phenomenon that occurs at the level of a supply chain rather than an individual firm, and it involves connections between firms. Further, RBV assumes reasonably predictable environments where the future value of resources is determinable (Kraaijenbrink et al. 2010). But SCRES has emergent characteristics due to the non-linear, dynamic and unpredictable nature of the environment to which it is a response. RBV also focuses on the component level - on the value of individual and separable resources; and it ignores their synergies, making it reductionist (e.g. Kraaijenbrink et al. 2010). In contrast, SCRES is a system level pattern emerging from the collective, dynamic and non-linear interactions between firms along the supply chain. As such, it could be argued that it can neither be objectively measured nor appropriately described using reductionist approaches (e.g. Brownlee 2007).

As with the RBV, both the dynamic capabilities model and contingency theory have a firm level focus and cannot adequately explain the systemic nature of SCRES. For example, dynamic capability models consider market dynamism and firm evolution over time (e.g. Wang \& Ahmed 2007). Meanwhile, contingency theory focuses on the fit between an organisational structure and its contingencies. Most of the other theories used thus far have similar shortcomings for studying SCRES. Systems theory is more promising for it recognises resilience as a systemic feature. However, today's supply chains go beyond traditional systems - they are complex systems with elements that continuously interact with each other and with their environment in an adaptive way. Their resilience is achieved through these adaptive and co-evolving processes. Therefore, an alternative theoretical lens that takes these features into account is required to make further progress in understanding and building SCRES. This study suggests that Complex Adaptive System (CAS) theory provides such a lens. Although Day (2014) used CAS theory, the author focused specifically on the resilience of disaster relief supply networks. These supply networks may, for example, be constructed to respond to high profile events for a discrete period of time. There are many other types of supply chains - including long-term supply chains that face continuous threats - that also need to be resilient, and to which features like adaptation and co-evolution may be even more relevant. Thus, this paper takes a broader approach and presents an elaboration of 
how the CAS lens can help to address most of the aforementioned gaps identified in the SCRES literature. In the next section, we outline the CAS framework as a candidate theoretical lens for studying SCRES. We introduce the theory and justify its choice as an appropriate theory for studying SCRES before outlining the implications of a CAS perspective for future SCRES research and practice.

\section{Complex Adaptive Systems: A Proposed Theory Lens for SCRES Research}

The term Complex Adaptive System (CAS) emerged from complexity theory (Nilsson 2003; Burnes 2004; Schneider \& Somers 2006; Brownlee 2007) and was initially applied to living systems (Surana et al. 2005; Wycisk et al. 2008). Complexity theory focuses on the emergence of order in dynamic and non-linear systems that operate at the edge of chaos (Fuller \& Moran 2001; Burnes 2004; Urry 2005). Since physical and social phenomena contain both chaos and order, complex nonlinear systems strive to be neither overly stable nor unstable. This is achieved through their order-generating rules, which facilitate transformation and self-organisation in order to remain at the edge of chaos amidst environmental changes (Burnes 2004). A CAS is regarded as a special kind of complex system due to the property of adaptation (Nilsson 2003; Surana et al. 2005) and can exist in unstable, but not completely chaotic environments (Innes \& Booher 1999).

Holland (1995) defined a CAS as a kind of system that, over a period of time, emerges into a coherent form through the aforementioned properties of adaptation and selforganisation. It consists of an interconnected network of multiple entities (or agents) that respond adaptively to changes in both the environment and the system of entities within it (Choi et al. 2001). In a CAS, adaptation implies that the system's agents or elements are responsive, flexible, reactive and often proactive in dealing with the inputs of other agents or elements that affect it (Nilsson 2003). The agents that constitute a CAS are guided by ordergenerating rules, also known as schemas (e.g. McCarthy 2003; Pathak et al. 2007; Hasgall, 2013), which determine how the CAS responds during the adaptation process. The CAS environment is rugged and dynamic; and CAS agents must adapt to maintain fit with the environment in a timely manner (Wycisk et al. 2008). During the adaptation process, new changes in the CAS and its environment may arise through a process of co-evolution (Choi et al. 2001), which makes it necessary to learn, thereby making appropriate modifications to schemas to increase fitness (Wycisk et al. 2008; Day 2014). But, equally, a CAS acts on and modifies its environment, and entities within the environment learn from the system's responses. 
The process of co-evolution in a CAS is also influenced by its non-linearity (Choi et al. 2001), which together with self-organisation and emergence has been considered a core feature of a CAS (McCarthy 2003, 2004; McCarthy et al. 2006). Non-linearity implies that there is an inconsistent relationship between the cause and effect of CAS events (Urry 2005), such that extreme events may yield disproportionately negative or positive results (Wycisk et al. 2008). Non-linearity may be influenced by the number and type of connections and interactions between the CAS agents (McCarthy et al. 2006). The degree of connectivity may also influence the extent to which the CAS agents act autonomously such that the higher the connectivity, the lower the agents' autonomy, and vice versa (Pathak et al. 2007).

Non-linearity in a CAS also produces self-organisation and emergence (McCarthy et al. 2006). Self-organisation and emergence refer to the synergistic effect of the decisions and actions of individual agents in a CAS that can cause changes, including the development of new structures, patterns and properties (Pathak et al. 2007). These changes may also be facilitated by the feature of scalability, which implies that different entities at different levels of a CAS have the same concerns; for example, reducing costs, increasing delivery speed and adaptation (Surana et al. 2005; Wycisk et al. 2008). As such, individual agents strive to achieve their goals by addressing their concerns, but end up causing the emergence of similar collective patterns at the wider system level.

\subsection{A CAS Theory Lens: Fit with Supply Chains and the Phenomenon of SCRES}

By its nature, a supply chain looks like a CAS (Choi et al. 2001; Surana et al. 2005; Pathak et al. 2007; Wycisk et al. 2008; Hearnshaw \& Wilson 2013; Day 2014) since it mirrors the main features of a CAS, as described in Table 8. Moreover, the property of resilience is one that is inherent to such a CAS. Hence, there appears to be a logical fit between the theoretical lens of CAS and the study of SCRES. A system is resilient to the extent that it can adapt to threats in its environment without violating its integrity as a system. Often, this involves modifying its environment (e.g. selecting and educating other economic actors), so it inherently involves co-evolution. It is also likely to be highly non-linear: we know, for example, that apparently minor changes in supply chain controls allow for catastrophic events to potentially occur. The most obvious example of this is the bullwhip effect, where a small distortion in the flow of orders downstream can cause a massive impact upstream in the supply chain (Pereira et al. 2009). The non-linearity and interdependence of SCRES can also be demonstrated by the fire in 2000 that gutted Philips' semiconductor plant - a key supplier of a critical cell phone component to both Nokia and Ericsson. This caused massive disruption, and it emerged that 
Ericsson was less resilient to this than Nokia. As a result, Nokia prospered while Ericsson registered a $\$ 1.7$ billion loss for the year and eventually went out of business (Hopkins 2005).

SCRES is manifested through the process of self-organisation - another property of a CAS - rather than as a result of being deliberately managed or controlled by a single firm. No single firm, however large it may be, can claim to manage and control the resilience of the entire supply chain. This is partly because a supply chain is complex to the extent that most of what happens therein is beyond the visibility and reach of a focal firm (Choi \& Krause 2006). Similarly, a survey by the Business Continuity Institute (2013) found that $75 \%$ of respondents lacked visibility of their supply chains. In addition, the study by Borekci et al. (2014) indicated that the overall resilience of a triad - referring here to a buying firm and two suppliers - is greater than the sum of the resilience of the individual entities. This further confirms the non-linear, self-organised and emergent nature of SCRES.

A structured comparison between the features of a CAS, a supply chain and SCRES is provided in Table 8. From Table 8, the features of a CAS - such as adaptation and coevolution, nonlinearity, network connectivity/interaction, dimensionality, self-organisation and emergence, and scalability - can be seen to be applicable to the notion of supply chains and, more specifically, to SCRES. The implications of adopting a CAS theory lens for studying SCRES will be discussed in the next subsection.

[Take in Table 8]

\subsection{Implications of a CAS Theory Lens for SCRES Research}

\subsubsection{The Use of Non-Reductionist Methodologies}

From a CAS perspective, resilience can be viewed as an emergent feature of a supply chain. Moreover, it emerges in a non-linear and dynamic manner as a synergy from the collective decisions and actions of individual firms (e.g. Day 2014). Similarly, SCRES emerges out of self-organising processes, which are less determinable as they may be spontaneous (Nilsson \& Gammelgaard 2012). Brownlee (2007) noted that system level patterns that emerge as a result of collective, dynamic and nonlinear interactions between individual adaptive agents cannot be described using reductionist methodologies. Thus, the deterministic or reductionist methodologies that have been used in SCRES research (e.g. Zsidisin \& Wagner 2010; Park 2011; Ponomarov 2012) may not fully explain the emergent or dynamic nature of SCRES. For example, statistical linear models used in survey research may not be appropriate since the emergent nature of resilience is different from a mere aggregation of individual supply chain elements. In addition, the CAS feature of nonlinearity implies that seemingly trivial 
events in the supply chain may result in significant threats, depicting a non-linear relationship between cause and effect (e.g. between SCRES and its antecedents). Thus, the few selected and seemingly fundamental variables in conceptual frameworks presented in the literature may not fully explain the resultant SCRES phenomena. Meanwhile, the presumably trivial independent variables often left out of these frameworks may have unexpectedly overwhelming effects. Although this was not earlier identified as a research gap, the CAS view demonstrates its relevance to further research on SCRES.

\subsubsection{The Need to Use Constructionist Approaches}

Building on the above, the CAS framework suggests that supply chains are under constantly changing adaptation pressures that lead to evolution and co-evolution. Indeed, being resilient is likely to be an adaptive and on-going process, making it difficult to predict or measure objectively. Moreover, prior studies have indicated that resilience is a socially constructed phenomenon that is also difficult to describe objectively (e.g. Ungar 2001, 2004; Walker et al. 2004). This implies that SCRES can best be studied using non-objective, constructionist methods, such as qualitative case studies and ethnography. This suggestion is supported by McCarthy et al. (2006) who recommended a multiple case study approach when researching CAS phenomena. Section 4 of this paper earlier highlighted the limited number of case studies and other empirical approaches that take resilience as a social construct (e.g. ethnography); hence, this is an important issue for future research.

\subsubsection{The Supply Network as the Unit of Analysis and the Need for Longitudinal Research}

The processes of co-evolution and self-organisation, and the emergence of collective behavioural patterns in a CAS, suggest that the resilience of a supply chain is not the result of an individual firm's actions in isolation. Instead, it is a network phenomenon arising from connectivity and interdependence between firms. This suggests that we should consider supply chains, rather than individual firms, as the unit of analysis. Moreover, most contemporary risk events have emerged at the level of networks rather than individual firms (Busby \& Alcock 2008). Although many scholars (e.g. Ponomarov 2012) have considered firms as the unit of analysis, it is important to observe that the resilience of a firm is determined by the resilience of its network (Sheffi \& Rice 2005; Wedawatta et al. 2010).

As noted above, SCRES involves non-linear and co-evolving processes. It also involves self-organisation and emergent behaviour, which keeps changing due to co-evolution. The behaviour patterns resulting from continuous adaptation and counter-adaptation cannot easily be understood at a single point in time; hence, longitudinal research is required. Yet the 
dominance of a cross-sectional approach in the current SCRES research was previously identified as a limitation of the existing body of literature in Section 4.

\subsubsection{The Learning Dimension of SCRES}

Co-evolution in a CAS implies that the implementation of SCRES strategies by certain firms may have influenced the actions of other firms along the supply chain as well as having influenced the environment itself. Subsequent changes in the environment may create more complexity - and therefore more threats - that may require further adaptation, sometimes requiring different strategies to those previously adopted. This indicates that resilience is a volatile phenomenon that is difficult to achieve and it confirms that there is unlikely to be an optimal level of SCRES. For example, a flexible resilience strategy, such as multiple sourcing (Hearnshaw \& Wilson 2013), may enlarge the supply base and add more complexity and threats, which may require more coordination and adaptation. Co-evolution also underscores the importance of mutual learning and counter-adaptation, both among firms within the supply network (producing emergent properties), and between supply networks and the environment during the process of creating SCRES. Although the learning dimension of SCRES was not identified as a gap in Section 4, earlier studies (e.g. Ponomarov \& Holcomb 2009) have considered it to be an important avenue for further research.

\subsubsection{The Phenomena of Risk Transfer and Migration}

Some of the features of a CAS, such as nonlinearity and co-evolution, suggest that decisions and policies may result in disproportionate and unpredictable effects (McCarthy 2003). Sometimes, these effects may be the opposite of those that firms along the network had originally intended (Urry 2005). Moreover, individual firm behaviours, driven by the need to survive, may lead to negative consequences for the entire system (Fuller \& Moran 2001). For example, increasing network connectivity and clustering in a CAS improves its resilience (Hearnshaw \& Wilson 2013), but strategies that increase network connectivity - like horizontal collaboration between suppliers - may increase supply chain risk through collusion (Choi \& Krause 2006). Thus, the CAS may be a useful framework for understanding risk transfer and migration, which has already been identified in Section 4 as a hindrance to SCRES and as an under-researched phenomenon.

\subsection{Implications of CAS Theory for Practice}

Adopting a CAS perspective reminds managers that supply networks are under constant adaptation pressures - some of these pressures may not be threats, but a response or 
adaptation within the network may itself trigger a threat. Managers must understand that there are some adaptations other than simple responses to economic pressures that produce supply chain risks, e.g. new organisations joining the network and the adoption of new initiatives and decision principles. In other words, a manager's own decisions, together with those of other actors within and outside the supply network contain latent risks that can potentially fail the network. This arguably calls for the adoption of real options reasoning to allow for flexible decisions that are able to respond to different manifestations of threats.

An example that can help to understand the practical implications of CAS for SCRES is the Sudan 1 crisis, where the food supply chain between India and the UK was infiltrated by carcinogen contaminated chilli powder. This led to intense media scrutiny, widespread panic, and product recalls that cost the industry approximately £100million (Busby \& Alcock 2008). This case provided a basic illustration of how complex system adaptations need to be understood by organisations trying to make supply chains resilient. The scandal itself arose from an adaption. Merchants chose from different consignments of chilli powder partly by appearance. Chilli powder tends to brown over time, so some growers adapted by incorporating a red dye in their consignments. The dye happened to be a suspected carcinogen. By the time the EU imposed import restrictions, a consignment containing the dye was already in the inventories of a UK food manufacturer, and the contaminated chilli was incorporated in a wide range of foodstuffs that reached the shelves of retailers. Understanding the potential for this kind of scandal therefore requires an appreciation of how adaptations occur within a supply network over time, and how these adaptations, and their products, become incorporated within the system. Furthermore, when the scandal broke, there was considerable alarm that bioterrorists could exploit similar weaknesses in food supply networks to distribute toxins to large populations. This in itself could be regarded as an adaptation within the wider social system: the adaptation of a potential attacker to a system that had evolved to rapidly and efficiently produce and distribute food products over a wide scale.

The CAS perspective also informs managers that in order to ensure SCRES, they must look at the supply chain holistically rather than isolating individuals and their actions from the whole. This may be aided by supply chain mapping to have a clear view of the entire relevant network. Otherwise, systemic resilience capabilities at a network level are likely to be lost as economic pressures to adapt are most likely felt acutely by individual nodes that have their own survival motives and are guided by particular schemas. One of the identified weaknesses in the Sudan 1 case was the failure to manage the proliferation of potential 
contaminable sources at certain levels of the supply network (Busby \& Alcock 2008), and this also shows that managers should avoid incorporating organisations in the network whose orientations are incompatible with a common response on threats. This relates to the CAS feature of scalability, which presupposes that agents at different levels have similar concerns or common schemas. It is such commonality which makes them perform activities that lead to consistent patterns at the network level that result in resilience.

\section{Conclusions}

This paper has provided a comprehensive, structured review of the available literature on Supply Chain Resilience (SCRES) based on the 91 papers identified from the systematic review procedure detailed in Section 2. The specific objectives were: to define supply chain resilience; analyse and classify the available literature on SCRES, identifying gaps in the literature and areas in need for further research; and to propose an appropriate theoretical lens for studying SCRES.

First, this paper has contributed to the definition of SCRES by formally integrating 'cost effectiveness'. It is important that a supply chain recovers from a disruption to the same or a better state than before, but it is also important that it does so at reasonable cost. This contributes to the literature as fully understanding what it means to be resilient is a fundamental prerequisite to achieving supply chain resilience. Second, the available literature was analysed according to the SCRES strategies studied, the research method applied, and the use of theory. A number of broad gaps were identified from the literature, providing a starting point for scholars to conduct further research into this important topic. For example, there is a need to:

- Study strategies for building SCRES other than flexibility, redundancy, collaboration, and agility, including how they can be implemented;

- Further understand SCRES strategy choices, including the synergies and trade-offs between SCRES strategies that may cause risk migration;

- Conduct longitudinal studies on SCRES, including in-depth studies of particular disruptions that threaten supply chains;

- Research SCRES in organisations and contexts neglected thus far, including in developing countries, small and medium sized enterprises and in service settings.

Third, Complex Adaptive Systems (CAS) theory was identified and justified as a promising lens for such future research on SCRES, and some of the implications of adopting 
a CAS perspective in SCRES research were discussed. These implications largely mirrored the gaps identified in the SCRES literature, which further confirmed that CAS can improve our understanding of SCRES. Finally, the implications of CAS theory for practice were briefly discussed with reference to the Sudan 1 disruption to the food supply chain.

\subsection{Limitations}

This study has two important limitations. First, our review relied on Onesearch and Google Scholar using predefined search strings and a limited time horizon. This may have limited the breadth of the search and potentially led to the omission of some sources of information. Measures were however taken to be comprehensive, as described in Section 2, while it was clearly important to limit the scope of our review in some way. Second, our study is confined to being a literature review that only proposes the use of CAS theory. Thus, empirical work that actually demonstrates the utility of CAS is beyond the scope of this paper. Yet, the review is in itself a noteworthy contribution by laying the theoretical foundations for future empirical studies on SCRES.

\section{References}

Adtiya, S., Kumar, S., Kumar, A., Datta, S., and Mahapatra, S., 2014. "A Decision Support System towards Suppliers' Selection in Resilient Supply Chain: Exploration of Fuzzy-TOPSIS.” International Journal of Management and International Business Studies 4(2): 159-168

Alcock, R. and Busby, J., 2006. "Risk Migration and Scientific Advance: The Case of Flame-Retardant Compounds." Risk Analysis 26(2): 369-381.

Allen, P., Datta, P., and Christopher, M., 2006. "Improving the resilience and performance of organizations using multi-agent modelling of a complex production - distribution systems." Risk Management (8): 294-309.

Asbjørnslett, B., 2009. "Assessing the vulnerability of supply chains." In: G.A. Zsidisin and B. Ritchie, eds. Supply chain risk: a handbook of assessment, management and performance. New York: Springer, $15-33$.

Avanzi, B., Bicer, I., De Treville, S., and Trigeorgis, L., 2013. "Real options at the interface of finance and operations: exploiting embedded supply-chain real options to gain competitiveness." The European Journal of Finance 19 (7-8):760-778.

Azevedo, S., Govindan, K., Carvalho, H., and Cruz-Machado, V., 2013. "Ecosilient Index to assess the greenness and resilience of the upstream automotive supply chain." Journal of Cleaner Production 56: $131-146$

Azevedo, S., Govindan, K., Carvalho, H., and Cruz-Machado, V., 2011 "GResilient index to assess the greenness and resilience of the automotive supply chain.” (8) 2011. Discussion Papers of Business and Economics. ISBN 978-87-91657-51-1. 
Barac, N., Milovanović, G., and Andjelković, A., 2011. "Risk and the resilient supply chain", Series: Economics and Organization 8 (2): 139 - 151.

Barksh, N. and Kleindorfer, P., 2009. "Co-opetition and investment for supply chain resilience." Production and operation management 18 (6): 583-603.

Barney, J., 1991. "Firm Resources and Sustained Competitive Advantage." Journal of Management 17 (1): 99-121.

Barroso, A., Machado, H., and Cruz-Machado, V., 2011. "The Resilience Paradigm in the Supply Chain Management: A Case Study.” Proceedings of the IEEE: 928-932.

Barroso, A., Machado, H., Barros, R., and Cruz-Machado, V., 2010. "Toward a Resilient Supply Chain with Supply Disturbances." Proceedings of the 2010 IEEE IEEM: 245-249.

Bhamra, R., Dani, S., and Burnard, K., 2011. "Resilience: the concept, a literature review and future directions." International Journal of Production Research 49 (18):5375-5393.

Bhattacharya, A., Geraghty, J., and Young, P., 2009. "On the Analytical Framework of Resilient SupplyChain Network Assessing Excursion Events." Third Asia International Conference on Modelling \& Simulation IEEE: 392-397.

Bhattacharya, A., Geraghty, J., Young, P., and Byrne, P., 2012. "Design of a resilient shock absorber for disrupted supply chain networks: a shock-dampening fortification framework for mitigating excursion events." Production Planning \& Control: The Management of Operations 24 (8-9): 721-742.

Bicer, I., 2015, "Dual sourcing under heavy-tailed demand: an extreme value theory approach", International Journal of Production Research, DOI: 10.1080/00207543.2015.1008111.

Blackhurst, J., Dunn, S., and Craighead, W., 2011. “An Empirically Derived Framework of Global Supply Resiliency." Journal of Business Logistics 32(4):374-391.

Boin, A, Kelle, P., and Whybark, C., 2010. "Resilient supply chains for extreme situations: Outlining a new field of study." International journal of production economics 126(1): 1-6.

Boone, C., Craighead, C., Hanna, B., and Nair, A., 2013. "Implementation of a System Approach for Enhanced Supply Chain Continuity and Resiliency: A Longitudinal Study." Journal of Business Logistics 34(3):222-235

Borekci, D., Rofcanin, Y., and Gürbüz, H., 2014. "Organisational resilience and relational dynamics in triadic networks: a multiple case analysis." International Journal of Production Research DOI:10.1080/00207543.2014.903346: 1-29

Brandon-Jones, E., Squire, B., Autry, C., and Petersen, K., 2014. "A contingent resource-based perspective of supply chain resilience and robustness." Journal of Supply Chain Management 50(3):55-73

Brennan, P., 2011. "Supply chain lessons learned from the Japan Earthquake", Disaster Recovery Journal 24(3): 22-26.

Briano, E, Caballini ,C., Giribone, P., and Revetria, R., 2010. "Objectives and perspectives for improving resiliency in Supply Chains." WSEAS transactions on systems 9(2): 136-145. 
Briano, E., Caballini, C., and Revetria, R., 2009. "Literature review about supply chain vulnerability and resiliency." Proceedings of the 8th WSEAS International Conference on systems science and simulation in engineering: 191-197.

Brownlee, J., 2007. "Complex Adaptive Systems." Complex Intelligent Systems Laboratory, Centre for Information Technology Research, Technical Report 070302A, Melbourne, Australia.

Bruneau, M., Chang, S., Eguchi, R., Lee, G., O’Rourke, T., Reinhorn, A., Shinozuka, M., Tierne,y K., Wallace, W., and Winterfeldt, D., 2003. "A Framework to Quantitatively Assess and Enhance the Seismic Resilience of Communities." Earthquake Spectra 19 (4): 733-752.

Burnes, B., 2004. "Kurt Lewin and complexity theories: back to the future?" Journal of Change Management 4(4):309-325.

Busby, J., and Alcock, R., 2008. "Risk and organisational networks: making sense of failure in division of labour." Risk Management 10(4): 235 - 256.

Business Continuity Institute., 2013: Supply Chain Resilience. 5th Annual Survey:1-17

Cabral, I, Grilo, A, Leal, P., and Machado, C., 2011. "Modelling Lean, Agile, Resilient, and Green Supply Chain Management." Proceedings of the ITI 2011 33rd Int. Conf. on Information Technology Interfaces, June 27-30: 365-370.

Cabral, I., Grilo, A., and Cruz-Machado, V., 2012. "A decision-making model for Lean, Agile, Resilient and Green supply chain management." International Journal of Production Research 50 (17): 48304845 .

Carvalho, H., Barroso, A., Machado, V., Azevedo, S., and Machado, V., 2011a. "Supply chain resilience. A simulation study." Annals of DAAAM for 2011 \& Proceedings of the 22nd International DAAAM Symposium 22 (1): 1611-1612.

Carvalho, H., Duarte, S., and Cruz Machado, V., 2011b. "Lean, agile, resilient and green: divergences and synergies.” International Journal of Lean Six Sigma 2 (2):151-179.

Carvalho, H., Azevedo, S., and Cruz-Machado, V., 2012a. "Agile and resilient approaches to supply chain management: influence on performance and competitiveness." Logistics Research 4 (1-2): 49-62.

Carvalho, H., Barroso, A., Machado, V., Azevedo, S., and Cruz-Machado, V., 2012b. "Supply chain redesign for resilience using simulation." Computers \& Industrial Engineering 62 (1): 329-341.

Carvalho, H., Cruz-Machado, V., and Tavares, G., 2012c. "A mapping framework for assessing Supply Chain resilience." International Journal of Logistics Systems and Management 12 (3): 354-373.

Carvalho, H., Maleki, M., and Cruz-Machado, V., 2012d. "The links between supply chain disturbances and resilience strategies." International Journal of Agile Systems and Management 5 (3): 203-234.

Chan, V., Lui, I., Lun, G., and Nagji, N., 2010. "From Nigeria to Benin: Applying a Vendor Awareness Initiative to Combat the Counterfeit Drug Trade." The Meducator 1 (17): 9-12.

Chen, J., Sohal, A., and Prajogo, D., 2013. "Supply chain operational risk mitigation: a collaborative approach.” International Journal of Production Research 51 (7): 2186-2199.

Chen, L. and Miller-Hooks, E., 2012. "Resilience: An Indicator of Recovery Capability in Intermodal Freight Transport." Transportation Science 46 (1): 109-123. 
Chika, A., Bello, S., Jimoh, A., and Umar, T., 2011. "The menace of fake drugs: consequences. Causes and possible solutions." Research Journal of Medical Sciences 5 (5): 257-261.

Choi, T. and Krause, D., 2006. "The supply base and its complexity: Implications for transaction costs, risks, responsiveness, and innovation.” Journal of Operations Management 24 (5): 637-652.

Choi, T., Dooley, K., and Rungtusanatham, M., 2001. "Supply networks and complex adaptive systems: control versus emergence." Journal of Operations Management 19 (3): 351-366.

Christopher, M. and Holweg, M., 2011. "Supply Chain 2.0: managing supply chains in the era of turbulence.” International Journal of Physical Distribution \& Logistics Management 41 (1): 63-82.

Christopher, M. and Lee, H., 2004. "Mitigating supply chain risk through improved confidence." International Journal of Physical Distribution \& Logistics Management 34 (5): 388 - 396.

Christopher, M. and Peck, H., 2004. "Building the resilient supply chain." International Journal of Logistics Management 15 (2): 1-13.

Christopher, M. and Rutherford, C., 2004. "Creating supply chain resilience through agile six sigma." Critical Eye Publications, June - August 2004: 24-28.

Cimellaro, G., Reinhorn, M., and Bruneau, M., 2010. "Seismic resilience of a hospital system." Structure and Infrastructure Engineering, 6 (1-2): 127-144.

Closs, D. and McGarrell, E., 2004."Enhancing security throughout the supply chain." IBM Center for the Business of Government, special report series: 1-52 http://www.businessofgovernment.org.

Colicchia, C., Dallaria, F., and Melacini, M., 2010. "Increasing supply chain resilience in a global sourcing context." Production Planning \& Control, 21 (7): 680-694.

Cox, A., Prager, W., and Rose, A., 2011. "Transportation security and the role of resilience: A foundation for Operational metrics." Transport Policy, 18 (2): 307-317.

Craig, N., DeHoratius, N., and Raman, A., 2014. "The Impact of Supplier Inventory Service Level on Retailer Demand in the Supply Chain for Functional Apparel items." Harvard Business School Technology \& Operations Management Unit Working Paper (11-034):1-34.

Craighead, C., Blackhurst, J., Rungtusanatham. J., and Handfield, R., 2007. "The severity of supply chain disruptions: Design characteristics and mitigation capabilities." Decision Sciences 38(1): 131-156.

Dahlman, O., 2008. "Towards a Resilient European Supply Chain", Sixteenth OSCE Economic and Environmental Forum, Vienna, 28- 29 January 2008:1-26.

Datta, P., 2007. "A complex system, agent based model for studying and improving the resilience of production and distribution networks." PhD Dissertation, Cranfield University.

Datta, P., Christopher, M., and Allen, P., 2007. "Agent-based modelling of complex production/distribution systems to improve resilience." International Journal of Logistics: Research and Applications 10(3):187-203.

Day, M., 2014. "Fostering emergent resilience: the complex adaptive supply network of disaster relief." International Journal of Production Research 52 (7):1970-1988 
Denyer, D. and Tranfield, D., 2009. "Chapter 39: Producing a Systematic Review": 671-689. The Sage Handbook of Organizational Research Methods, Editors Buchanan, D. and Bryman, A., Sage Publications Ltd, London. ISBN: 978-1-4129-3118-2.

Diabat, A., Govindan, K., and Panicker, V., 2012 "Supply chain risk management and its mitigation in a food industry." International Journal of Production Research 50 (11): 3039-3050.

Erol, O., Sauser, B., and Mansouri, M., 2010. "A framework for investigation into extended enterprise resilience." Enterprise Information Systems 4 (2):111-136.

Fakoor, A., Olfat, L., Feizi, K., and Amiri, M., 2013. "A Method for Measuring Supply Chain Resilience in the Automobile Industry." Journal of Basic and Applied Scientific Research 3 (2): 537-544.

Falasca, M., Zobel, C., and Cook, D., 2008. "A Decision Support Framework to Assess Supply Chain Resilience." Fiedrich F. and Van de Walle B, (Ed.), Proceedings of the 5th International ISCRAM Conference - Washington, DC, USA: 596-605.

Fang, H., Li, C., and Xiao, R., 2012. "Supply Chain Network Design Based on Brand Differentiation and Resilient Management.” Journal of Information \& Computational Science 9(14): 3977-3986.

Fiksel, J., 2003. "Designing Resilient, Sustainable Systems." Environmental Science and Technology 37 (23):5330-5339.

Finch, P., 2004. "Supply chain risk management", Supply Chain Management: An International Journal 9 (2):183 - 196.

Foy, R., Ovretveit, J., Shekelle, P., Pronovost, P., Taylor S., Sydney, D., Hempel, S., McDonald M., Rubenstein, L., Wachter, R., 2011. "The role of theory in research to develop and evaluate the implementation of patient safety practices." BMJ Quality and Safety 20(5):453-459.

Fuller, T. and Moran, P., 2001. "Small enterprises as complex adaptive systems: a methodological question?” Entrepreneurship \& Regional Development: An International Journal 13(1):47-63.

Gaonkar, R. and Viswanadham, N., 2007. "Analytical Framework for the Management of Risk in Supply Chains." IEEE Transactions on Automation Science and Engineering, 4 (2): 265-273.

Geng, L., Xiao, R., and Xu, X., 2014. "Research on MAS-Based Supply Chain Resilience and Its SelfOrganized Criticality." Discrete Dynamics in Nature and Society 2014: 1-14

Ghadge, A., Dani, S., and Kalawsky, R., 2012. "Supply chain risk management: present and future scope." The International Journal of Logistics Management 23(3):313-339.

Glickman, T. and White, S., 2006. "Security, visibility and resilience: the keys to mitigating supply chain vulnerabilities." International Journal of Logistics Systems and Management 2 (2):107-119.

Golgeci, I. and Ponomarov, S., 2013. "Does firm innovativeness enable effective responses to supply chain disruptions? An empirical study." Supply Chain Management: An International Journal 18(6):604-617

Gould, J., Macharis, C., and Haasis, H.,2010. "Emergence of security in supply chain management Literature." Journal of transport security 3(4):287-302.

Grabowski, M., and Roberts, K., 1997 "Risk Mitigation in Large-Scale Systems; Lessons from high reliability organisations." California management review39 (4):152-162. 
Guoping, C. and Xinqiu, Z., 2010a. "Research on resilient supply chain on the basis of Hooke's law." Proceedings of the IEEE: 1-3.

Guoping, C. and Xinqiu, Z., 2010b. "Research on Supply Chain Resilience Evaluation." Proceedings of the 7th International Conference on Innovation \& Management:1558-1562.

Habermann, M., 2009. "Identifying and Mitigating the Antecedents of Supply Chain Disruptions - 3 Essays", PhD Dissertation, The university of Minnesota.

Haimes, Y., 2006. "On the Definition of Vulnerabilities in Measuring Risks to Infrastructures." Risk Analysis 26 (2): 293-296.

Haimes, Y., Crowther, K., and Horowitz, B., 2008. "Homeland security preparedness: balancing protection with resilience in emergent systems." Systems Engineering 11(4): 287-308.

Hamel, G. and Valikangas, L., 2003. “The quest for resilience.” Harvard Business Review 81(9):52-63

Hasgall, A., 2013. "Digital social networks as complex adaptive systems." The journal of information and knowledge management systems 43(1):78-95.

Hearnshaw, E., and Wilson, M., 2013. "A complex network approach to supply chain network theory." International Journal of Operations \& Production Management 33 (4): 442-469.

Hendricks, K., and Singhal, V., 2005. "Association between Supply Chain Glitches and Operating Performance." Management Science 51 (5): 695-711.

Hendricks, K., and Singhal, V., 2003. "The effect of supply chain glitches on shareholder wealth." Journal of Operations Management 21(5): 501-522

Holland, J., 1995. "Hidden order: how adaptation builds complexity." Addison Wesley Longman Publishing Co., Inc. Redwood City, CA, USA.

Hopkins, K., 2005. "Value opportunity three: improving the ability to fulfil demand." Business Week, 13 January 2005.

Hu, Y., Li, J., and Holloway, L., 2010. “Achieving Resilience for a Class of Serial Production Networks”, American Control Conference:5326-5331, Marriott Waterfront, USA.

Innes, J. and Booher, D., 1999. "Consensus Building and Complex Adaptive Systems." Journal of the American Planning Association 65(4): 412-423.

Ishfaq, R., 2012. "Resilience through flexibility in transportation operations." International Journal of Logistics Research and Applications 15 (4): 215-229.

Ivanov, D., Sokolov, B., and Dolgui, A., 2014. "The Ripple effect in supply chains: trade-off 'efficiencyflexibility-resilience' in disruption management." International Journal of Production Research 52(7):2154-2172

Ji, G., and Zhu, C., 2008. "Study on supply chain disruption risk management strategies and model." Proceedings of the IEEE International Conference on Service Systems and Service Management: 1-6, June 30-July 2, Melbourne, Australia.

Jiang, Y., Zhao, L., and Sun, S., 2009. "A resilient strategy for meat-food supply chain network design." Proceedings of the IEEE IEEM: 1479-1483. 
Johnson, N., Elliott, D., and Drake, P., 2013. "Exploring the role of Social Capital in facilitating Supply Chain resilience." Supply Chain Management: An International Journal, 18 (3):324 - 336.

Jost, J., 2004. "External and internal complexity of complex adaptive systems", Theory in biosciences 123(1):69-88.

Jüttner, U. and Maklan, S., 2011. "Supply chain resilience in the global financial crisis: an empirical study.” Supply Chain Management: An International Journal 16 (4): 246-259.

Jüttner, U., Peck, H., and Christopher, M., 2003. "Supply Chain Risk Management: Outlining an Agenda for Future Research.” International Journal of Logistics: Research \& Applications 6(4):197-210.

Klibi, W., and Martel, A., 2012. "Modeling approaches for the design of resilient supply networks under disruptions." International Journal of Production Economics, 135 (2): 882-898.

Kong, X. and Li, X., 2008. "Creating the Resilient Supply Chain: The Role of Knowledge Management Resources." proceedings of the IEEE Wireless Communications, Networking and Mobile Computing: $1-4$.

Kraaijenbrink, J., Spender, C., and Groen, J., 2010. "The Resource-Based View: A Review and Assessment of Its Critiques." Journal of Management 36(1):349-372.

Kristianto, Y., Gunasekaran, A., Helo, P., and Hao, Y., 2014. "A model of resilient supply chain network design: A two-stage programming with fuzzy shortest path.” Expert Systems with Applications 41(1): $39-49$

Lakovou, E., Vlachos, D., and Xanthopoulos, A., 2007. "An analytical methodological framework for the optimal design of resilient supply chains." International Journal of Logistics Economics and Globalisation 1(1):1-20.

Leat, P., and Revoredo-Giha, C., 2013. "Risk and resilience in agri-food supply chains: the case of the ASDA PorkLink supply chain in Scotland." Supply Chain Management: An International Journal, 18 (2): $219-231$.

Lee, H., 2004.“The triple-A supply chain.” Harvard Business Review 82 (10): pp. 102-112.

Levesque, P., 2012."Building resilience and sustainability into the Chinese supply chain." Global Business and Organizational Excellence 31(3):69-83

Li, Y., and Zhao, L., 2010. "Analysing Deformation of Supply Chain Resilient System Based on Cell Resilience Model." Li et al. (Eds.): LSMS/ICSEE 2010, Part I LNCS 6328: 26-35.

Longo, F., and Oren, T., 2008. "Supply chain vulnerability and resilience: a state of the art overview." Campora S. Giovanni (CS) (Ed.), Proceedings of European Modeling \& Simulation Symposium, 17-19 September 2008, Italy.

Mandal, S., 2012. “An Empirical Investigation into Supply Chain Resilience.” The IUP Journal of Supply Chain Management 9 (4):46-61.

Martin, W., Martin, I., and Kent, B., 2009. "The role of risk perceptions in the risk mitigation process: The case of wildfire in high risk communities." Journal of Environmental Management 91(2):489-498.

Mascaritolo, J. and Holcomb, C., 2008. "Moving towards a resilient supply chain." Journal of transportation management 19 (2): 71-83. 
McCarthy, P., 2003. "Technology management - a complex adaptive systems approach.” International Journal of technology management 25(8):728-745.

McCarthy, P., 2004. "Manufacturing strategy: understanding the fitness landscape.” International Journal of Operations \& Production Management 24(2):124-150.

McCarthy, P., Tsinopoulos, C., Allen, P., and Rose-Anderssen, C., 2006. "New Product Development as a Complex Adaptive System of Decisions." Journal of production innovation management, 23(5):437456.

Mensah, P. and Merkuryev, Y., 2014. "Developing a resilient supply chain.” Procedia - Social and Behavioral Sciences 110: 309 - 319

Mitra, K., Gudi, R., Patwardhan, S., and Sardara, G., 2009. "Towards resilient supply chains: Uncertainty analysis using fuzzy mathematical programming." Chemical Engineering Research and Design 87(7):967-981.

Murino, T., Romano, E., and Santillo, L., 2011. "Supply chain performance sustainability through resilience function", S. Jain, R.R. Creasey, J. Himmelspach, K.P. White, and M. Fu, (Ed.), Proceedings of the 2011 Winter Simulation Conference.

Nilsson, F. and Gammelgaard, B., 2012. "Moving beyond the systems approach in SCM and logistics research.” International Journal of Physical Distribution \& Logistics Management 42(8/9):764-783.

Nilsson, F., 2003. "A Complex Adaptive Systems Approach on Logistics - Implications of adopting a complexity perspective" Lund University, ISBN 91-974611-7-2.

Nishiguchi, T. and Beaudet, A., 1998. "The Toyota group and the Aisin fire." Sloan Management Review 40(1): 49-59.

Palin, P., 2013. "Supply Chain Resilience: Diversity + Self-organization $=$ Adaptation." Home land security affairs 9(14):1-11.

Park, K., 2011. "Flexible and Redundant Supply Chain Practices to Build Strategic Supply Chain Resilience: Contingent and Resource-based Perspectives." PhD Dissertation, The University of Toledo.

Pathak, D., Day, J., Nair, A., Sawaya, W., and Kristal, M., 2007. "Complexity and adaptivity in supply chain networks: building supply network theory using a complex adaptive systems perspective." Decision Sciences, 38 (4):547-62.

Peck, H., 2005. "Drivers of supply chain vulnerability: an integrated framework." International Journal of Physical Distribution \& Logistics Management 35(4):210 - 232.

Pereira, J., Takahashi, K., Ahumada, L., and Paredes, F., 2009. "Flexibility dimensions to control the bullwhip effect in a supply chain." International Journal of Production Research 47(22):6357-6374.

Peters, C., 2010. "Improving supply chain resilience with network-centric manufacturing." DSN innovations white paper: $1-9$.

Pettit, J., Croxton, K., and Fiksel, J., 2013. "Ensuring Supply Chain Resilience: Development and Implementation of an Assessment Tool.” Journal of Business Logistics 34(1):46-76.

Pettit, J., Fiksel. J., and Croxton, K., 2010. "Ensuring supply chain resilience: Development of a conceptual frame work." Journal of business logistics 31(1):1-21. 
Pettit, T., 2008. "Supply chain resilience. Development of a conceptual frame work, an assessment tool and an implementation process." PhD Dissertation, The Ohio State University.

Pfohl, H., Holger, K., and Thomas, D., 2010. "State of the art in supply chain risk management research: Empirical and conceptual findings and a roadmap for the implementation in practice." Logistics Research (2):33-44.

Ponis, S., and Koronis, E., 2012. "Supply Chain Resilience: Definition of Concept and Its Formative Elements.” Journal of Applied Business Research 28(5):921-930.

Ponomarov, S., 2012. "Antecedents and consequences of supply chain resilience: A Dynamic Capabilities Perspective." PhD Dissertation, University of Tennessee-USA.

Ponomarov, S., and Holcomb, C., 2009. "Understanding the concept of supply chain resilience." International Journal of Logistics Management 20(1):124 - 143.

Ratick, S., Meacham, B., and Aoyama, Y., 2008. "Locating Backup Facilities to Enhance Supply Chain Disaster Resilience." Growth and Change 39(4):642-666.

Reserve Bank of Australia., 2011. "The Japanese earthquake and global supply chains.” Statement on monetary policy: 17-20. http://www.rba.gov.au/publications/smp/boxes/2011/aug/a.pdf

Rice, J. and Caniato, F., 2003. "Building a secure and resilient supply network." Supply chain management review 7(5): 22-30.

Saenz, J. and Revilla, E., 2014. "Creating More Resilient Supply Chains.” MIT Sloan management review summer, 2014: 22-24

Sawik ,T., 2013. "Selection of resilient supply portfolio under disruption risks." Omega 41(2): 259-269.

Schlegel, G. and Trent, R., 2012. "Risk management, Welcome to the new normal." Supply chain management review 16(1):42-45.

Schneider, M. and Somers, M., 2006. "Organizations as complex adaptive systems: Implications of Complexity Theory for leadership research.” The Leadership Quarterly 17(4):351-365.

Scholten, K., Scott, P., Fynes, B., 2014. "Mitigation processes - antecedents for building supply chain resilience." Supply Chain Management: An International Journal 19(2): 211-228

Seuring, S. and Müller, M., 2008. "From a literature review to a conceptual framework for sustainable supply chain management." Journal of Cleaner Production 16(15):1699-1710.

Sheffi, Y. and Rice, J., 2005. "A supply chain view of the resilient enterprise." MIT Sloan management review 47(1):41-48.

Sheffi, Y., 2005. "Building a resilient supply chain.” Harvard Business Review 1(8):1-11.

Shuai, Y., Wang, X., and Zhao, L., 2011. "Research on Measuring Method of Supply Chain Resilience Based on Biological Cell Elasticity Theory." Industrial Engineering and Engineering Management (IEEM), IEEE International Conference: 264-268.

Singhal, P., Agarwal, G., and Mittal, M., 2011. "Supply chain risk management: review, classification and future research directions." International Journal of Business Science and Applied Management 6 (3):15-42. 
Smith, A. and Vidal, J., 2010. "A Practical Multi- agent Model for Resilience in Commercial Supply Networks, Twelfth International Workshop on Agent-Mediated Electronic Commerce (AMEC):1-14.

Sodhi, S., Son, B., and Tang, C., 2012. "Researchers perspectives on supply chain risk management." Production and operations management 21(1):1-13.

Soni, U. and Jain, V., 2011. "Minimizing the Vulnerabilities of Supply Chain: A new Framework for Enhancing the Resilience." Proceedings of the IEEE IEEM: 933-939.

Spiegler, V., Naim, M., and Wikner, M., 2012. "A control engineering approach to the assessment of supply chain resilience.” International Journal of Production Research 50(21):6162-6187.

Spink, J., 2011. "Risk assessment and mitigation with focus on Anti-Counterfeiting." Supply Chain World North America Conference, May 25, 2011, Michigan State University:1-20.

Stecke, K. and Kumar, S., 2009. "Sources of Supply Chain Disruptions, Factors That Breed Vulnerability, and Mitigating Strategies.” Journal of Marketing Channels 16(3):193-226.

Stevenson, M. and Spring, M., 2007. "Flexibility from a supply chain perspective: definition and review." International Journal of Operations \& Production Management 27(7):685 - 713.

Stewart, G., Kolluru, R., and Smith, M., 2009."Leveraging public-private partnerships to improve community resilience in times of disaster." International Journal of Physical Distribution \& Logistics Management 39 (5): 343-364.

Sullivan-Taylor, B. and Branicki, L., 2011. "Creating resilient SMEs: why one size might not fit all." International Journal of Production Research 49(18):5565-5579.

Surana, A., Kumara, S., Greaves, M., and Raghavan, U., 2005. "Supply-chain networks: a complex adaptive systems perspective." International Journal of Production Research 43 (20):4235-4265.

Tang, C. and Tomlin, B., 2008. "The power of flexibility for mitigating supply chain risks." International journal of production Economics 116(1):12-27.

Tang, C., 2006a. "Perspectives in supply chain risk management." International Journal of Production Economics103 (2): 451-488.

Tang, C., 2006b. "Robust strategies for mitigating supply chain disruptions." International Journal of Logistics: Research and Applications 9(1):33-45.

Teece, D., 2007. "Explicating dynamic capabilities: the nature and micro foundations of (sustainable) enterprise performance.” Strategic Management Journal 28(13):1319-1350.

Thun, J ., Drüke, M., and Hoenig, D., 2011. "Managing uncertainty - an empirical analysis of supply chain risk management in small and medium sized enterprises." International Journal of Production Research 49(18):5511-5525.

Tranfield, D., Denyer, D., and Smart, P., 2003. "Towards a Methodology for Developing EvidenceInformed Management Knowledge by Means of Systematic Review.” British Journal of Management 14 (3):207-222.

Transparency International., 2013. "Corruption Perceptions Index 2013.”

Ungar, M., 2001."The Social Construction of Resilience among "Problem" Youth in Out-of-Home Placement: A Study of Health-Enhancing Deviance." Child \& Youth Care Forum, 30(3):137-154. 
Ungar, M., 2004. "A Constructionist Discourse on Resilience: Multiple Contexts, Multiple Realities among At-Risk Children and Youth." Youth \& Society 35(3):341-365.

Urciuoli, L., Mohanty, S., Hintsa, J., and Boekesteijn, E., 2014. "The resilience of energy supply chains: a multiple case study approach on oil and gas supply chains to Europe." Supply Chain Management: An International Journal 19(1):46-63

Urry, J., 2005. "The Complexities of the Global.” Theory Culture and Society 22(5):235-254.

Vlachos, D., Iakovou, E., Papapanagiotou, K., and Partsch, D., 2012. "Building robust supply chains by reducing vulnerability and improving resilience." International Journal of Agile Systems and Management 5(1):59-81.

Vugrin, E., Warren, E., and Ehlen, A., 2011.“A Resilience Assessment Framework for Infrastructure and Economic Systems: Quantitative and Qualitative Resilience Analysis of Petrochemical Supply Chains to a Hurricane." Process Safety Progress 30(3):280-290.

Wagner, S. and Bode, C., 2006. "An empirical investigation into supply chain vulnerability." Journal of Purchasing \& Supply Management 12(6):301-312.

Wagner, S. and Bode, C., 2008. "An empirical examination of supply chain performance along several dimensions of risk." Journal of business logistics 29(1):307-325.

Wagner, S. and Neshat, N., 2012. "A comparison of supply chain vulnerability indices for different categories of firms." International Journal of Production Research 50(11): 2877-2891.

Wakolbinger, T. and Cruz J., 2011. "Supply chain disruption risk management through strategic information acquisition and sharing and risk-sharing contracts." International Journal of Production Research 49(13):4063-4084.

Walker, B., Carpenter, H., and Kinzig, A., 2004. "Resilience, Adaptability and Transformability in Socialecological Systems." Ecology and Society 9(2):1-9

Wang, C. and Ahmed, K., 2007. "Dynamic capabilities: a review and research agenda." The International Journal of Management Reviews 9(1):31-51.

Wang, W., Muddada, R., Huang., and Zhang, J., 2013. "On Petri net implementation of proactive resilient holistic supply chain networks." International Journal of Advanced Manufacturing Technology 69(14):427-437

Wedawatta, G., Ingirige ,B., and Amaratunga, D., 2010. "Building up resilience of construction sector SMEs and their supply chains to extreme weather events." International Journal of Strategic Property Management 14(4):362-375.

Wernerfelt, B., 1984. “A Resource-Based View of the Firm.” Strategic Management Journal 5(2):17180.

Wieland, A. and Wallenburg, C., 2013. "The influence of relational competencies on supply chain resilience: A relational view." International Journal of Physical Distribution \& Logistics Management 43(4):300 - 320 .

Wilding, R., and Wagner, B., 2014."Building theory in supply chain management through "systematic reviews" of the literature." Supply Chain Management: An International Journal 19(5/6): 1-8. 
Williams, Z., Jason, E., Lueg, E., and LeMay, S., 2008. "Supply chain security: An overview and research agenda." The International Journal of Logistics Management 19 (2):254 - 281.

World economic Forum., 2012. "Reducing Supply Chain Barriers Could Increase Global GDP Up to Six Times More Than Removing All Import Tariffs.”:1-4.

World Economic Forum., 2013. "Building Resilience in Supply Chains.": 1-41

Wycisk, C., McKelvey, B., and Hülsmann, M., 2008. "Smart parts supply networks as complex adaptive systems: analysis and implications." International Journal of Physical Distribution \& Logistics Management 38(2):108 - 125.

Xiao, R., Yu, T., and Gong, X., 2012. "Modeling and simulation of ant colony's labor division with constraints for task allocation of resilient supply chains." International Journal on Artificial Intelligence Tools 21(3):1-19.

$\mathrm{Xu}$, J., 2008. "Managing the Risk of Supply Chain Disruption: Towards a Resilient Approach of Supply Chain Management." ISECS International Colloquium on Computing, Communication, Control, and Management IEEE: 3-7.

Xu, M., Wang, X., and Zhao, L., 2014. "Predicted supply chain resilience based on structural evolution against random supply disruptions.” International Journal of Systems Science: Operations \& Logistics 1(2): $105-117$

Yan, N. and Sun, B., 2010. "Robust Optimization of Multi-sourcing Strategies in Resilient Supply Chain." International Conference on Management Science \& Engineering (17th) November 24-26, IEEE: 477481.

Yanfeng, H., 2011. "Resilient Supply Chain System Coordinating: Mechanism Designing for Emergence Produced." Proceedings of the IEEE: 581-584.

Yang, B. and Yang, Y., 2010. "Postponement in supply chain risk management: a complexity perspective." International Journal of Production Research 48(7):1901-1912.

Yao, Y. and Meurier, B., 2012. "Understanding the supply chain resilience: a Dynamic Capabilities approach." 9es Rencontres Internationales de la Recherche en Logistique: 1-17.

Zhang, D., Dadkhah, P., and Ekwall D., 2011. "How robustness and resilience support security business against antagonistic threats in transport network.” Journal of Transport Security 4(3): 201-219.

Zhao, K., Kumar, A., Harrison, P., and Yen, J., 2011. "Analysing the resilience of complex supply network topologies against random and targeted disruptions." IEEE systems journal 5(1):28-39.

Zobel, C., 2010. "Comparative Visualization of Predicted Disaster Resilience." Proceedings of the 7th International ISCRAM Conference - Seattle, USA: 1-6.

Zsidisin, G. and Wagner, S., 2010. "Do perceptions become reality? The moderating role of supply chain resiliency on disruption occurrence.” Journal of Business Logistics 31(2):1-20. 
Figure 1: Overview of Review Process - Sourcing, Screening and Analysing the Articles

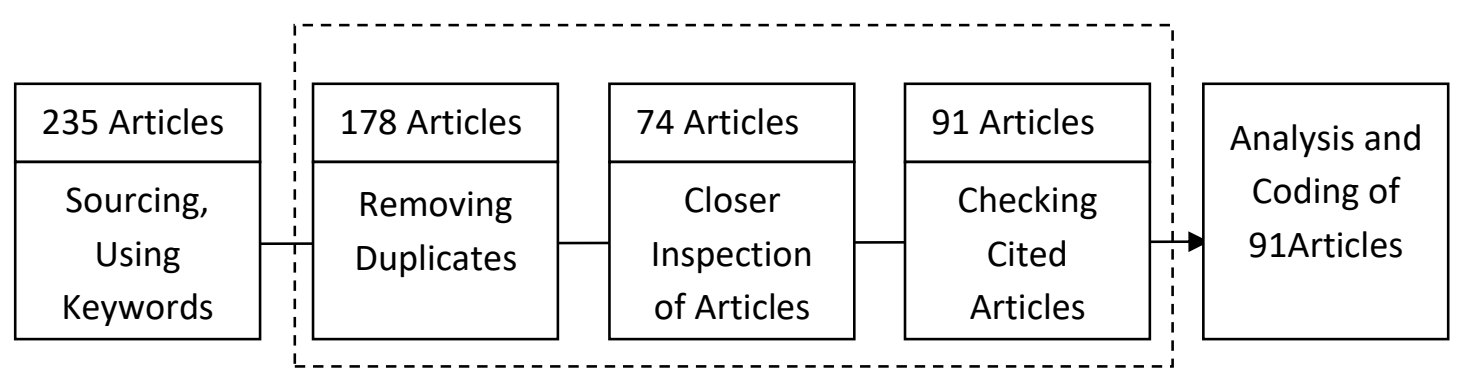

\section{Screening}

Figure 2: Operationalising Supply Chain Resilience

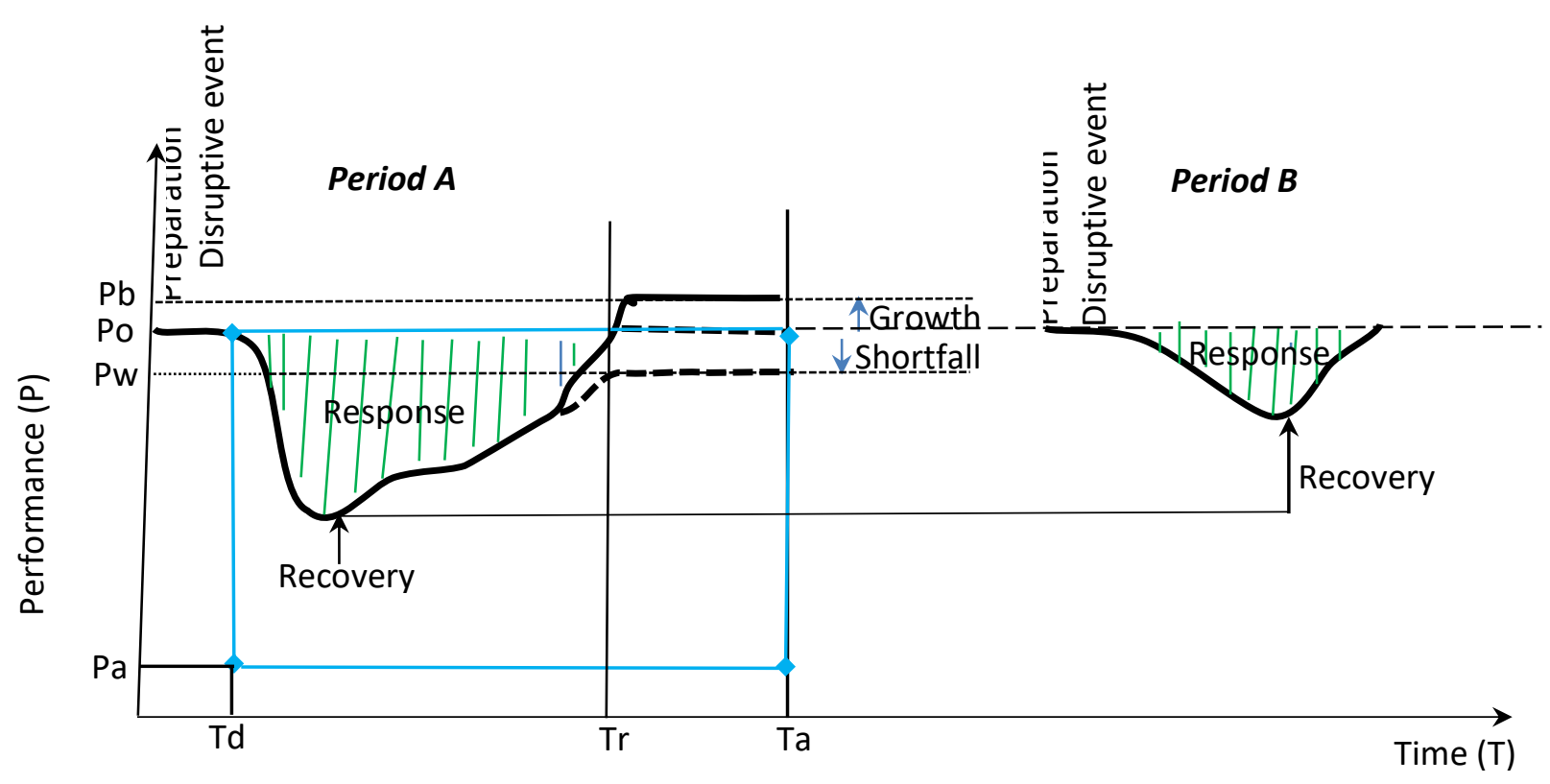


Figure 3: Categorisation of 91 SCRES Papers based on Research Method

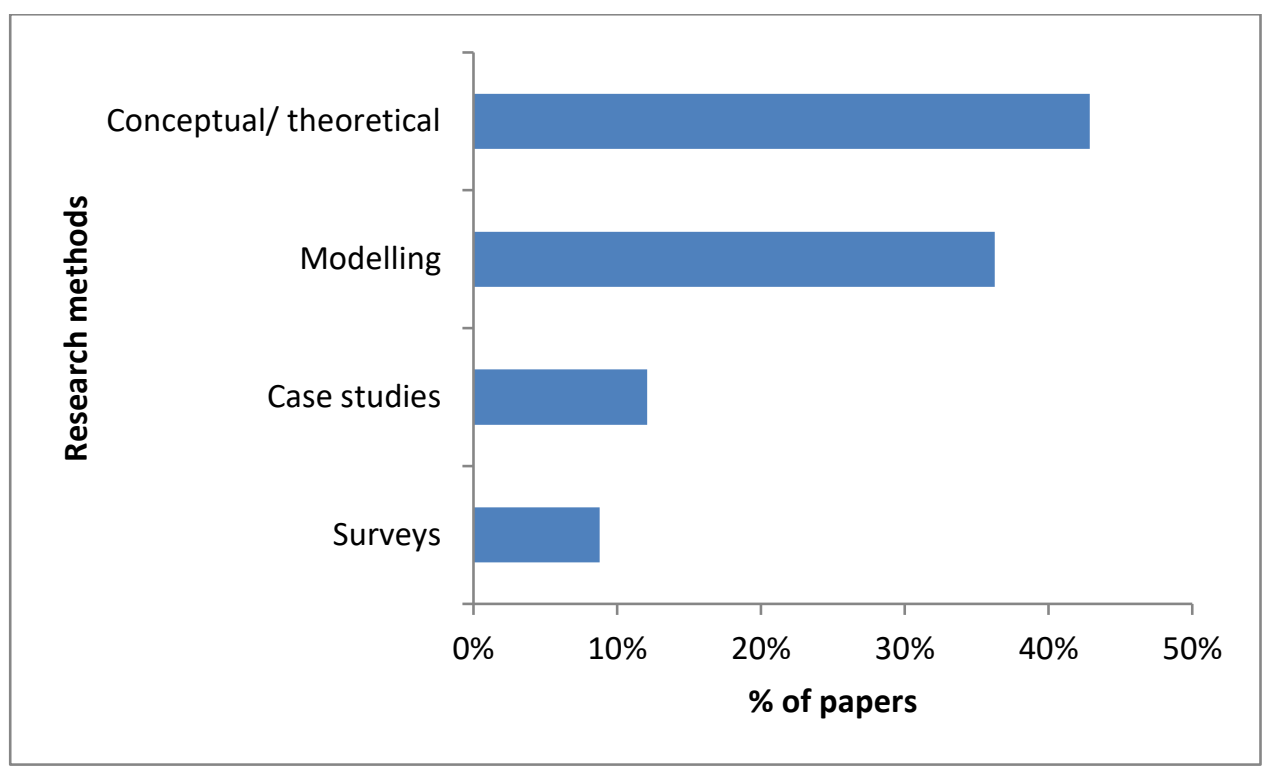


Table 1: List of Journals Publishing SCRES Research To Date

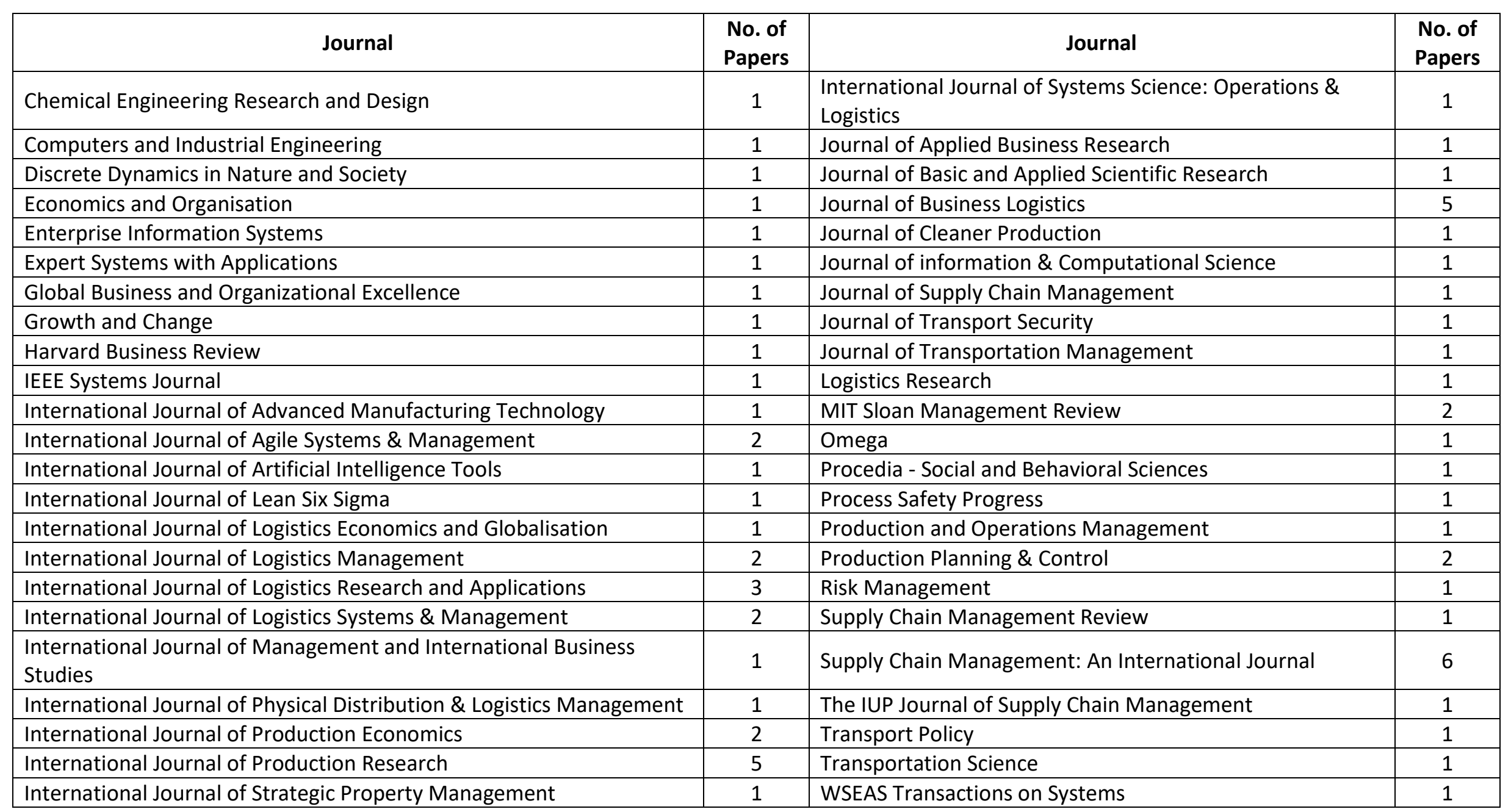


Table 2a: Existing Definitions of Supply Chain Resilience from the Literature

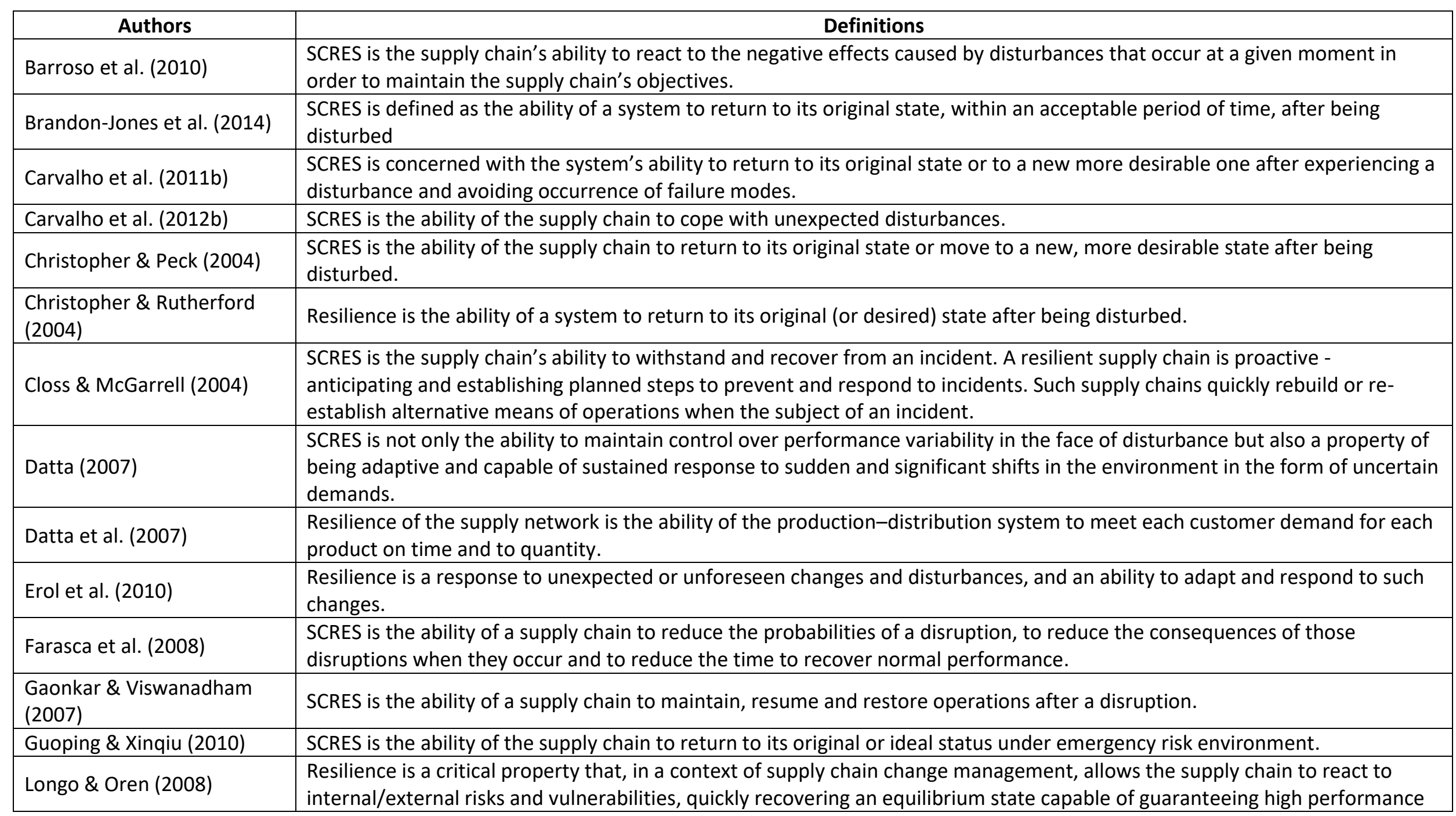




\begin{tabular}{|l|l|}
\hline & and efficiency levels. \\
\hline Pettit et al. (2010) & Supply chain resilience is the ability to survive, adapt and grow in the face of turbulent change. \\
\hline Ponis \& Koronis (2012) & $\begin{array}{l}\text { SCRES is the ability to proactively plan and design the supply chain network for anticipating unexpected disruptive (negative } \\
\text { events), respond adaptively to disruptions while maintaining control over structure and function and transcending to a post } \\
\text { robust state of operations, if possible a more favourable one than that prior to the event, thus gaining a competitive } \\
\text { advantage. }\end{array}$ \\
\hline $\begin{array}{l}\text { Ponomarov \& Holcomb } \\
\text { (2009) }\end{array}$ & $\begin{array}{l}\text { SCRES is the adaptive capability of the supply chain to prepare for unexpected events, respond to disruptions, and recover } \\
\text { from them by maintaining continuity of operations at the desired level of connectedness and control over structure and } \\
\text { function. }\end{array}$ \\
\hline Ponomarov (2012) & $\begin{array}{l}\text { SCRES is the adaptive capability of a firm's supply chain to prepare for unexpected events, respond to disruptions, and } \\
\text { recover from them in a timely manner by maintaining continuity of operations at the desired level of connectedness and } \\
\text { control over structure and function. }\end{array}$ \\
\hline Rice \& Caniato (2003) & $\begin{array}{l}\text { Resilience in the supply network environment is the ability to react to unexpected disruption and restore normal supply } \\
\text { network operations. }\end{array}$ \\
\hline Sheffi (2005) & $\begin{array}{l}\text { Resilience in terms of the corporate world is the ability of the company to bounce back from a large disruption including the } \\
\text { speed with which it returns to a normal level of performance. }\end{array}$ \\
\hline Shuai et al. (2011) & $\begin{array}{l}\text { Resilience is defined as the rapid recovery ability to equilibrium after the supply chain is attacked by a disturbance and we use } \\
\text { the recovery time to measure the ability. }\end{array}$ \\
\hline Xiao et al. (2012) & $\begin{array}{l}\text { SCRES is the supply chain's ability to return to the original or ideal status after external disruption and includes both the } \\
\text { abilities of adaptability to the environment and recovery from the disruption. }\end{array}$ \\
\hline Yao \& Meurier (2012) & $\begin{array}{l}\text { Supply resilience is defined as the ability to bounce back from disruptions and to permanently deal with and respond to the } \\
\text { changing environment. }\end{array}$ \\
\hline
\end{tabular}


Table 2b: Key Characteristics of Existing Definitions of SCRES

\begin{tabular}{|c|c|c|c|c|c|c|c|c|c|c|c|c|c|}
\hline Characteristics & 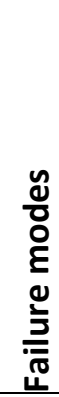 & 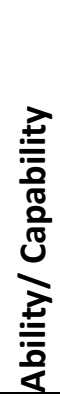 & $\begin{array}{l}\frac{2}{3} \\
\frac{10}{0} \\
\frac{0}{\pi} \\
\frac{0}{0} \\
\frac{\pi}{0}\end{array}$ & 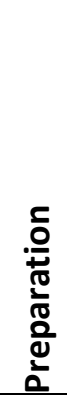 & 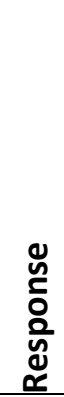 & 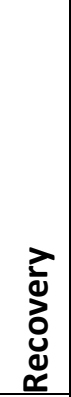 & $\stackrel{\stackrel{g}{\xi}}{\underline{\xi}}$ & 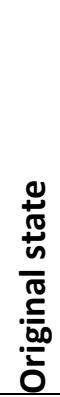 & 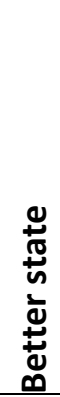 & 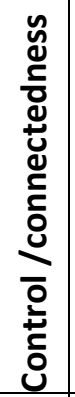 & 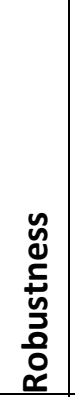 & 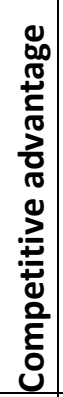 & 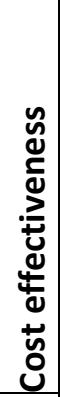 \\
\hline Barroso et al. (2010) & & $\mathrm{X}$ & & & $\mathrm{X}$ & & & $\mathrm{X}$ & & & & & \\
\hline Brandon-Jones et al. (2014) & & $\mathrm{X}$ & & & & & $\mathrm{X}$ & $\mathrm{X}$ & & & & & \\
\hline Carvalho et al. (2011b) & $\mathrm{X}$ & $\mathrm{X}$ & & & & $\mathrm{X}$ & & $\mathrm{X}$ & $\mathrm{X}$ & & & & \\
\hline Carvalho et al. (2012b) & & $\mathrm{X}$ & $\mathrm{X}$ & & $\mathrm{X}$ & & & & & & & & \\
\hline Christopher \& Peck (2004) & & $x$ & & & $x$ & $\mathrm{x}$ & & $\mathrm{x}$ & $\mathrm{X}$ & & & & \\
\hline Christopher \& Rutherford (2004) & & $\mathrm{X}$ & & & $\mathrm{x}$ & $\mathrm{x}$ & & $x$ & $x$ & & & & \\
\hline Closs \& McGarrell (2004) & & $\mathrm{X}$ & & $\mathrm{X}$ & $\mathrm{X}$ & $\mathrm{X}$ & $\mathrm{X}$ & & & & & & \\
\hline Datta (2007) & & $\mathrm{X}$ & $\mathrm{X}$ & & $\mathrm{x}$ & & & $\mathrm{X}$ & $\mathrm{X}$ & & & & \\
\hline Datta et al. (2007) & & $\mathrm{X}$ & & & $\mathrm{x}$ & & $\mathrm{X}$ & & & & & & \\
\hline Erol et al. (2010) & & $\mathrm{X}$ & $\mathrm{X}$ & & $\mathrm{X}$ & & & & & & & & \\
\hline Farasca et al. (2008) & & $x$ & & $\mathrm{x}$ & $x$ & $\mathrm{X}$ & $\mathrm{X}$ & $\mathrm{X}$ & & & & & \\
\hline Gaonkar \& Viswanadham (2007) & & $x$ & & & $x$ & $x$ & & $x$ & & & & & \\
\hline Guoping \& Xinqiu (2010) & & $\mathrm{x}$ & & & & $\mathrm{x}$ & & $x$ & $\mathrm{X}$ & & & & \\
\hline Longo \& Oren (2008) & & & & & $\mathrm{X}$ & $x$ & & $x$ & $x$ & & & & \\
\hline Pettit et al. (2010) & & $x$ & $x$ & & $x$ & & & & $\mathrm{X}$ & & & & \\
\hline Ponis \& Koronis (2012) & & $x$ & $x$ & $x$ & $x$ & $\mathrm{X}$ & & $\mathrm{X}$ & $x$ & $\mathrm{X}$ & $\mathrm{X}$ & $\mathrm{X}$ & \\
\hline Ponomarov \& Holcomb (2009) & & $x$ & $\mathrm{x}$ & $\mathrm{x}$ & $x$ & $x$ & & $x$ & $x$ & $\mathrm{X}$ & & & \\
\hline Ponomarov (2012) & & $x$ & $x$ & $x$ & $\mathrm{x}$ & $\mathrm{x}$ & $\mathrm{X}$ & $\mathrm{x}$ & $\mathrm{x}$ & $x$ & & & \\
\hline Rice \& Caniato (2003) & & $x$ & & & $x$ & $x$ & & & & & & & \\
\hline Sheffi (2005) & & $\mathrm{x}$ & & & & $\mathrm{X}$ & $\mathrm{X}$ & $\mathrm{X}$ & & & & & \\
\hline Shuai et al. (2011) & & $x$ & & & & $x$ & $x$ & $\mathrm{x}$ & $\mathrm{X}$ & & & & \\
\hline Xiao et al. (2012) & & $x$ & $\mathrm{X}$ & & & $x$ & & $x$ & $x$ & & & & \\
\hline Yao \& Meurier (2012) & & $\mathrm{X}$ & & & $\mathrm{X}$ & $\mathrm{X}$ & & $\mathrm{X}$ & & & & & \\
\hline
\end{tabular}




\begin{tabular}{|c|c|}
\hline Argument for Inclusion & Authors \\
\hline $\begin{array}{l}\text { Resilient capabilities in the aspect of logistics and supply chain management should enable cost effective minimisation of } \\
\text { vulnerabilities. }\end{array}$ & Asbjørnslett (2009) \\
\hline There is a need to minimize the expected cost of mitigation when building SCRES. & Bakshi \& Kleindorfer (2009) \\
\hline A resilient supply chain should be able to cope with disruptions with minimal losses. & Barac et al. (2011) \\
\hline $\begin{array}{l}\text { The attributes which are capable of enhancing the firm's supply resilience are those that increase its ability to quickly and } \\
\text { efficiently recover from disruptive phenomena. }\end{array}$ & Blackhurst et al. (2011) \\
\hline Too high investments in creating SCRES may overshadow its marginal benefits. & Brandon-Jones et al. (2014) \\
\hline Lean (cost minimisation and waste elimination) and resilience can co-exist in supply chain management. & Cabral et al. (2012) \\
\hline Time and cost are key performance indicators of resilient supply chains. & Carvalho et al. (2011b) \\
\hline Supply chain resilience strategies should provide efficient and effective response. & $\begin{array}{l}\text { Carvalho et al.( 2012d); } \\
\text { Carvalho et al.(2012c) }\end{array}$ \\
\hline Network resilience should be measured considering the cost, time and resources incurred in the recovery process. & Chen \& Miller-Hooks (2012) \\
\hline SCRES can be created efficiently and cost effectively through the agile six sigma approach. & $\begin{array}{l}\text { Christopher \& Rutherford } \\
(2004)\end{array}$ \\
\hline Investment in SCRES-building measures should be balanced against the need to maintain a cost-efficient supply chain. & Dahlman (2008) \\
\hline SCRES strategies, such as maintaining enough slack, should not adversely affect the normal operational efficiency. & Datta (2007) \\
\hline Through flexible system optimization, a resilient supply network can be realised both effectively and efficiently. & Fang et al. (2012) \\
\hline $\begin{array}{l}\text { Resilience aims to recover the desired values of the states of a system not only within an acceptable time but also at an } \\
\text { acceptable cost. }\end{array}$ & $\begin{array}{l}\text { Haimes (2006); Haimes et al. } \\
\text { (2008) }\end{array}$ \\
\hline Disruptions should be mitigated at minimum cost in order to achieve an optimum state of SCRES. & Ivanov et al. (2014) \\
\hline A supply chain should be designed in such a way that it is resilient as well as optimal in its operations. & Mandal (2012) \\
\hline Optimisation models aim to allocate limited resources among mitigation strategies in order to achieve SCRES cost effectively. & $\begin{array}{l}\text { Ratick et al. (2008); Sawik } \\
(2013)\end{array}$ \\
\hline $\begin{array}{l}\text { Strategies for enhancing SCRES, such as increasing safety inventory and improving the efficiency of reserve capacity should be } \\
\text { within the cost margins. }\end{array}$ & Shuai et al. (2011) \\
\hline $\begin{array}{l}\text { An increase in relationship resources results in increased network resilience, but such resources should not be increased } \\
\text { beyond a certain limit, where it is not cost effective. }\end{array}$ & Smith \& Vidal (2010) \\
\hline $\begin{array}{l}\text { The resilience of a system involves its ability to use the lowest possible amount of resources during recovery processes. The } \\
\text { system that incurs the lower resilience costs will be considered the more resilient one. }\end{array}$ & Vugrin et al. (2011) \\
\hline
\end{tabular}


Table 4: Summary of Proactive and Reactive SCRES Strategies and Corresponding Authors

\begin{tabular}{|c|c|c|}
\hline & $\begin{array}{l}\text { Supply Chain Resilience Strategies } \\
\end{array}$ & Corresponding Authors \\
\hline \multirow{12}{*}{ 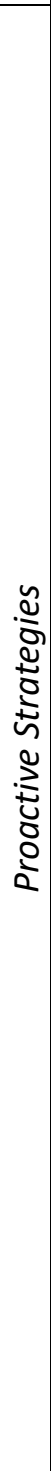 } & $\begin{array}{l}\text { Appropriate supplier selection - Using selection criteria that can help to minimise } \\
\text { disruptions and their impact, such as political stability in suppliers' territories, quality, } \\
\text { capabilities (e.g. technological), financial stability, business continuity, reliability, etc. }\end{array}$ & Mascaritolo \& Holcomb (2008) \\
\hline & $\begin{array}{l}\text { Building logistics capabilities - Capabilities for managing supply and information flows } \\
\text { necessary for minimising vulnerabilities, e.g. risk hedging capabilities, information } \\
\text { technology upgrades, and information sharing. }\end{array}$ & Ponomarov \& Holcomb (2009); Ponomarov (2012) \\
\hline & $\begin{array}{l}\text { Building security - Measures to protect the supply chain against deliberate disruptions, } \\
\text { e.g. theft, terrorism \& the infiltration of counterfeits }\end{array}$ & $\begin{array}{l}\text { Rice \& Caniato (2003); Pettit (2008); Barksh \& Kleindorfer (2009); Pettit et } \\
\text { al. (2010); Park (2011); Fakoor et al. (2013) }\end{array}$ \\
\hline & $\begin{array}{l}\text { Building social capital and relational competences - Effective communication and } \\
\text { information sharing before the risk event increases risk awareness and limits } \\
\text { vulnerability, e.g. communication, cooperation, trust, reciprocity, etc. }\end{array}$ & Johnson et al. (2013); Wieland \& Wallenburg (2013) \\
\hline & $\begin{array}{l}\text { Coopetition - Creating and maintaining collaboration between competitors so as to gain } \\
\text { from synergies, e.g. sharing resources for building security \& resilience. }\end{array}$ & Barksh \& Kleindorfer (2009); Borekci et al. (2014) \\
\hline & $\begin{array}{l}\text { Creating appropriate contractual agreements - Long term and short term contracts that } \\
\text { can enable flexibility in supply to minimise shortages. }\end{array}$ & Tang (2006a, 2006b); Urciuoli et al. (2014) \\
\hline & $\begin{array}{l}\text { Creating public-private partnerships - Contractual agreement between a public agency } \\
\text { and a private sector entity to share skills \& assets, risks and rewards in order to deliver } \\
\text { services or facilities to the general public. It increases government interest in private } \\
\text { entities' supply chains. }\end{array}$ & Stewart et al. (2009); Urciuoli et al. (2014) \\
\hline & $\begin{array}{l}\text { Creating risk management culture - Ensuring that all organisational members embrace } \\
\text { supply chain risk management, and this involves, e.g. top management support and firm } \\
\text { integration/team work. }\end{array}$ & $\begin{array}{l}\text { Christopher \& Peck (2004); Sheffi \& Rice (2005); Sheffi (2005); Xu (2008); } \\
\text { Zhang et al. (2011); Mandal (2012); Leat \& Revoredo (2013) }\end{array}$ \\
\hline & $\begin{array}{l}\text { Increasing innovativeness - The motivation and capability to seek and invent new } \\
\text { business ideas, e.g. new products, technologies, processes and strategies that can } \\
\text { reduce vulnerability. }\end{array}$ & Golgeci \& Ponomarov (2013) \\
\hline & $\begin{array}{l}\text { Increasing visibility - The ability to see through the entire supply chain (all nodes and } \\
\text { links), which helps to identify potential threats. }\end{array}$ & $\begin{array}{l}\text { Glickman \& White (2006); Datta et al. (2007); Lakovou et al. (2007); Longo } \\
\text { \& Oren (2008); Pettit (2008); Pettit et al. (2010); Zhang et al. (2011); } \\
\text { Carvalho et al. (2012b); Saenz \& Revilla (2014) }\end{array}$ \\
\hline & $\begin{array}{l}\text { Inventory management - The strategic alignment of inventory management using a } \\
\text { system-wide approach to minimise inventory risks }\end{array}$ & Boone et al. (2013) \\
\hline & Knowledge management - Developing knowledge and understanding of supply chain & Rice \& Caniato (2003); Christopher \& Peck (2004); Xu (2008); Kong \& Li \\
\hline
\end{tabular}




\begin{tabular}{|c|c|c|}
\hline & $\begin{array}{l}\text { structures (i.e. physical and informational), and the ability to learn from changes as well } \\
\text { as educate other entities. }\end{array}$ & $\begin{array}{l}\text { (2008); Ponis \& Koronis (2012); Ponomarov \& Holcomb (2009); Lakovou et } \\
\text { al. (2007); Jüttner \& Maklan (2011); Scholten et al. (2014) }\end{array}$ \\
\hline & $\begin{array}{l}\text { Portfolio diversification- Indulging in different products to reduce dependence on } \\
\text { particular products and suppliers. }\end{array}$ & Urciuoli et al. (2014) \\
\hline & $\begin{array}{l}\text { Supplier development - Facilitating suppliers with incentives, e.g. financial, training and } \\
\text { technical knowledge to improve efficiency, commitment and reliability. }\end{array}$ & Tang (2006b); Leat \& Revoredo (2013) \\
\hline & $\begin{array}{l}\text { Supply chain collaboration - The ability to work effectively with other supply chain } \\
\text { entities for mutual benefit, e.g. sharing information and other resources to reduce } \\
\text { vulnerability. }\end{array}$ & $\begin{array}{l}\text { Rice \& Caniato (2003); Christopher \& Peck (2004); Datta et al. (2007); } \\
\text { Mascaritolo \& Holcomb (2008); Pettit (2008); Ji \& Zhu (2008); Bakshi \& } \\
\text { Kleindorfer (2009); Ponomarov \& Holcomb (2009); Pettit et al. (2010); } \\
\text { Pettit et al. (2013); Barroso et al. (2010); Erol et al. (2010); Peters (2010); } \\
\text { Jüttner \& Maklan (2011); Zhang et al. (2011); Park (2011); Soni \& Jain } \\
\text { (2011); Mandal (2012); Ponis \& Koronis (2012); Carvalho et al. (2012b); } \\
\text { Leat \& Revoredo (2013); Fakoor et al. (2013); Scholten et al. (2014) }\end{array}$ \\
\hline & $\begin{array}{l}\text { Supply chain network structure/design - Constructing the supply chain network for } \\
\text { resilience, e.g. balancing redundancy, efficiency, vulnerabilities, etc. }\end{array}$ & $\begin{array}{l}\text { Datta et al. (2007); Diabat et al. (2012); Carvalho et al. (2012a); Mandal } \\
\text { (2012); Leat \& Revoredo (2013); Scholten et al. (2014) }\end{array}$ \\
\hline & $\begin{array}{l}\text { Sustainability compliance - Compliance to economic, social and environmental } \\
\text { requirements to mitigate associated supply chain risks, e.g. reputational risks. }\end{array}$ & Soni \& Jain (2011) \\
\hline & $\begin{array}{l}\text { Use of information technology - Information technology enhances connectivity and } \\
\text { supports other resilience strategies, e.g. visibility and collaboration, which can help in } \\
\text { signalling potential disruptions. }\end{array}$ & Kong \& Li (2008); Erol et al. (2010) \\
\hline & $\begin{array}{l}\text { Building logistics capabilities - Capabilities for supply and information flows, e.g. to } \\
\text { reduce cycle times, increase delivery competence, knowledge management and } \\
\text { customer service to quickly recover from a disruption. }\end{array}$ & Ponomarov \& Holcomb (2009); Ponomarov (2012) \\
\hline 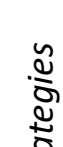 & $\begin{array}{l}\text { Building social capital and relational competences - Effective communication, trust and } \\
\text { information sharing can enable rapid access to resources necessary for recovery, e.g. } \\
\text { communication, cooperation, trust, reciprocity, etc. }\end{array}$ & Johnson et al. (2013); Wieland \& Wallenburg (2013) \\
\hline 壳 & $\begin{array}{l}\text { Contingency planning - Anticipating potential events and specifying the measures to } \\
\text { deal with supply chain risks and disruptions before they actually occur, e.g. by } \\
\text { forecasting and monitoring early warning signals. }\end{array}$ & $\begin{array}{l}\text { Glickman \& White (2006); Tang (2006b); Pettit (2008); Mascaritolo \& } \\
\text { Holcomb (2008) Pettit et al. (2010); Park (2011); Vlachos et al. (2012); } \\
\text { Urciuoli et al. (2014) }\end{array}$ \\
\hline$\stackrel{2}{2}$ & $\begin{array}{l}\text { Creating redundancy - The strategic and selective use of spare capacity and inventory } \\
\text { that can be used to cope with disruptions, e.g. spare stocks, multiple suppliers and extra } \\
\text { facilities. }\end{array}$ & $\begin{array}{l}\text { Rice \& Caniato (2003); Christopher \& Rutherford (2004); Sheffi (2005); } \\
\text { Sheffi \& Rice (2005); Peck (2005); Tang (2006b); Lakovou et al. (2007); Xu } \\
\text { (2008); Ratick et al. (2008); Longo \& Oren (2008); Ji \& Zhu (2008); Zsidisin } \\
\text { \& Wagner (2010); Carvalho et al. (2011b); Park (2011); Azevedo et al. } \\
\text { (2011); Diabat et al. (2012); Carvalho et al. (2012d); Ponis \& Koronis }\end{array}$ \\
\hline
\end{tabular}




\begin{tabular}{|c|c|}
\hline & $\begin{array}{l}\text { (2012); Vlachos et al. (2012); Xu et al. (2014); Urciuoli et al. (2014); Saenz \& } \\
\text { Revilla (2014) }\end{array}$ \\
\hline $\begin{array}{l}\text { Demand management - Mitigating the impact of disruptions by influencing customer } \\
\text { choices through, e.g. dynamic pricing, assortment planning and silent product rollovers. }\end{array}$ & (Tang 2006b); Urciuoli et al. (2014) \\
\hline $\begin{array}{l}\text { Ensuring supply chain agility - The ability to respond quickly to unpredictable changes in } \\
\text { demand and/or supply. }\end{array}$ & $\begin{array}{l}\text { Christopher \& Rutherford (2004); Christopher \& Peck (2004); Kong \& Li } \\
\text { (2008); Tang \& Tomlin (2008); Longo \& Oren (2008); Ji \& Zhu (2008); Erol et } \\
\text { al. (2010); Peters (2010); Carvalho et al. (2011b); Ponis \& Koronis (2012); } \\
\text { Carvalho et al. (2012b); Mandal (2012); Scholten et al. (2014) }\end{array}$ \\
\hline $\begin{array}{l}\text { Increasing flexibility - The ability of a firm and supply chain to adapt to changing } \\
\text { requirements with minimum time and effort. }\end{array}$ & $\begin{array}{l}\text { Rice \& Caniato (2003); Sheffi, (2005); Sheffi \& Rice (2005); Tang (2006b); } \\
\text { Glickman \& White (2006); Lakovou et al. (2007); Datta et al. (2007); Xu } \\
\text { (2008); Pettit(2008); Ratick et al. (2008); Tang \& Tomlin (2008); } \\
\text { Mascaritolo \& Holcomb (2008); Longo \& Oren (2008); Ji \& Zhu (2008); } \\
\text { Zsidisin \& Wagner (2010); Pettit et al. (2010); Erol et al. (2010); Zhang et al. } \\
\text { (2011); Azevedo et al. (2011); Soni \& Jain (2011); Carvalho et al. (2011b); } \\
\text { Park (2011); Xiao et al. (2012); Ishfaq (2012); Diabat et al.(2012); Carvalho } \\
\text { et al. (2012a); Ponis \& Koronis (2012); Vlachos et al. (2012); Carvalho et al. } \\
\text { (2012b); Fakoor et al. (2013); Azevedo et al. (2013); Mensah \& Merkuryev } \\
\text { (2014); Geng et al. (2014) }\end{array}$ \\
\hline $\begin{array}{l}\text { Increasing velocity - The pace of flexible adaptations that can determine the recovery } \\
\text { speed of the supply chain from a disruption. }\end{array}$ & Longo \& Oren (2008); Carvalho et al. (2012b) \\
\hline $\begin{array}{l}\text { Increasing visibility - The ability to see through the entire supply chain (all nodes and } \\
\text { links) so as to effectively respond to a disruption. }\end{array}$ & $\begin{array}{l}\text { Longo \& Oren (2008); Pettit (2008); Pettit et al. (2010); Soni \& Jain (2011); } \\
\text { Carvalho et al. (2011b); Zhang et al. (2011); Azevedo et al. (2011); Azevedo } \\
\text { et al. (2013); Brandon-Jones et al. (2014); Saenz \& Revilla (2014) }\end{array}$ \\
\hline $\begin{array}{l}\text { Supply chain collaboration - The ability to work effectively with other supply chain } \\
\text { entities for mutual benefit, e.g. sharing information and other resources necessary for } \\
\text { response and recovery. }\end{array}$ & $\begin{array}{l}\text { Rice \& Caniato (2003); Sheffi (2005); Datta et al. (2007); Mascaritolo \& } \\
\text { Holcomb (2008); Pettit (2008); Ji \& Zhu (2008); Ponomarov \& Holcomb } \\
\text { (2009); Pettit et al. (2010); Pettit et al. (2013); Erol et al. (2010); Peters } \\
\text { (2010); Jüttner \& Maklan (2011); Zhang et al. (2011); Park (2011); Soni \& } \\
\text { Jain (2011); Barac et al. (2011); Carvalho et al. (2011b); Ponis \& Koronis } \\
\text { (2012); Leat \& Revoredo (2013); Scholten et al. (2014) }\end{array}$ \\
\hline $\begin{array}{l}\text { Use of information technology - Information technology enhances connectivity and } \\
\text { supports other resilience strategies, e.g. visibility and collaboration, which can help in } \\
\text { coordinating responses to disruptions. }\end{array}$ & Kong \& Li (2008); Erol et al. (2010) \\
\hline
\end{tabular}


Table 5: Overview of Empirical Research on SCRES

\begin{tabular}{|c|c|c|c|c|c|}
\hline Authors & Focus & Methodology & Description & $\begin{array}{l}\text { Research } \\
\text { Design }\end{array}$ & Country \\
\hline $\begin{array}{l}\text { Rice \& Caniato } \\
(2003)\end{array}$ & $\begin{array}{l}\text { Secure and resilient } \\
\text { supply chains to terrorist } \\
\text { attacks }\end{array}$ & Case Study & $\begin{array}{l}\text { Case study of } 20 \text { medium and large scale companies ranging from } \\
\text { high-tech and aerospace to pharmaceuticals and consumer } \\
\text { packaged goods. }\end{array}$ & Cross-sectional & USA \\
\hline Pettit et al. (2010) & $\begin{array}{l}\text { SCRES through matching } \\
\text { capabilities with } \\
\text { vulnerabilities }\end{array}$ & Case Study & $\begin{array}{l}\text { Case study/ focus group of a apparel and beauty care products } \\
\text { retailer. } 8 \text { separate focus groups were conducted, each as an } \\
\text { individual case study. }\end{array}$ & Cross-sectional & USA \\
\hline $\begin{array}{l}\text { Blackhurst et al. } \\
\text { (2011) }\end{array}$ & $\begin{array}{l}\text { Enablers and inhibitors of } \\
\text { supply resilience }\end{array}$ & Case Study & $\begin{array}{l}\text { Case study of an automobile manufacturer, two suppliers and a } \\
\text { distributor; and a pharmaceuticals manufacturer with more than } \\
100,000 \text { employees, three retailers and two logistics providers. }\end{array}$ & Cross-sectional & $\begin{array}{l}\text { USA, China, } \\
\text { Korea }\end{array}$ \\
\hline $\begin{array}{l}\text { Johnson et al. } \\
\text { (2013) }\end{array}$ & $\begin{array}{l}\text { Social capital and SCRES: } \\
\text { UK rail crash }\end{array}$ & Case Study & $\begin{array}{l}\text { Case study of The Lambrigg, UK rail crash. Data collected from } 3 \\
\text { separate tiers of the supply chain. }\end{array}$ & Cross-sectional & UK \\
\hline $\begin{array}{l}\text { Leat \& } \\
\text { Revoredo (2013) }\end{array}$ & $\begin{array}{l}\text { Developing resilient agri- } \\
\text { food supply }\end{array}$ & Case Study & $\begin{array}{l}\text { Case study of the ASDA Pork-Link supply chain involving } 7 \\
\text { respondents. }\end{array}$ & Cross-sectional & UK \\
\hline Pettit et al. (2013) & $\begin{array}{l}\text { An assessment tool for } \\
\text { supply chain resilience }\end{array}$ & Case Study & $\begin{array}{l}\text { Case study of } 7 \text { global manufacturing and service firms and focus } \\
\text { groups (global retailer of personal care, beauty, and apparel } \\
\text { products, electronics, medical transportation firm operating as a } \\
\text { non-profit firm, personal care items, building materials and } \\
\text { chemicals). }\end{array}$ & Cross-sectional & USA \\
\hline $\begin{array}{l}\text { Borekci et al. } \\
\text { (2014) }\end{array}$ & $\begin{array}{l}\text { Relational dynamics and } \\
\text { resilience in buyer- } \\
\text { supplier triads }\end{array}$ & Case Study & $\begin{array}{l}\text { Case study of eight buyers and their suppliers from the textile } \\
\text { industry in Turkey }\end{array}$ & Cross-sectional & Turkey \\
\hline
\end{tabular}




\begin{tabular}{|c|c|c|c|c|c|}
\hline $\begin{array}{l}\text { Scholten et al. } \\
\text { (2014) }\end{array}$ & $\begin{array}{l}\text { Mitigation processes and } \\
\text { SCRES }\end{array}$ & Case Study & $\begin{array}{l}\text { Case study of the Voluntary Organisations Active in Disaster (VOAD); } \\
\text { nine interviews in three different VOAD lead member organisations. }\end{array}$ & Cross-sectional & USA \\
\hline $\begin{array}{l}\text { Urciuoli et al. } \\
\text { (2014) }\end{array}$ & $\begin{array}{l}\text { Strategies for building the } \\
\text { resilience of energy } \\
\text { supply chains }\end{array}$ & Case Study & $\begin{array}{l}\text { Case study of five companies operating in the energy market, } \\
\text { including oil and gas. }\end{array}$ & Cross-sectional & EU \\
\hline $\begin{array}{l}\text { Jüttner \& Maklan } \\
\text { (2011) }\end{array}$ & $\begin{array}{l}\text { SCRES capabilities in a } \\
\text { global financial crisis }\end{array}$ & Case Study & $\begin{array}{l}\text { Case study of } 3 \text { large firms: a chemical products supplier, a timber } \\
\text { wholesaler and a cabling supplier. }\end{array}$ & Longitudinal & $\begin{array}{c}\text { Not } \\
\text { indicated }\end{array}$ \\
\hline Boone et al. (2013) & $\begin{array}{l}\text { Strategic alignment of } \\
\text { inventory and SCRES }\end{array}$ & Case Study & $\begin{array}{l}\text { Field study involving } 10 \text { United States Air Force (USAF) locations and } \\
\text { two years of data. }\end{array}$ & Longitudinal & USA \\
\hline $\begin{array}{l}\text { Zsidisin \& Wagner } \\
\text { (2010) }\end{array}$ & $\begin{array}{l}\text { SCRES practices, supply } \\
\text { risk sources and } \\
\text { disruption occurrences }\end{array}$ & Survey & $\begin{array}{l}\text { Survey conducted within } 5 \text { large companies in construction, paper } \\
\text { and other capital equipment, aircraft manufacture, and material } \\
\text { handling equipment industries. The sample size used was } 499 \text { and } \\
\text { the response rate was } 59.3 \% \text {. }\end{array}$ & Cross-sectional & $\begin{array}{l}\text { USA \& } \\
\text { Germany }\end{array}$ \\
\hline Park (2011) & $\begin{array}{l}\text { Flexibility and } \\
\text { redundancy practices } \\
\text { related to SCRES }\end{array}$ & Survey & $\begin{array}{l}\text { Survey of } 71 \text { U.S. and South Korean firms with a response rate of } \\
4.7 \% \text { and } 22.8 \% \text {, respectively. More than half of the respondents } \\
\text { were from SMEs. }\end{array}$ & Cross-sectional & $\begin{array}{l}\text { USA \& South } \\
\quad \text { Korea }\end{array}$ \\
\hline Mandal (2012) & Antecedents of SCRES & Survey & Survey of 141 IT executives with a response rate of $36.91 \%$. & Cross-sectional & India \\
\hline Ponomarov (2012) & $\begin{array}{l}\text { Antecedents and } \\
\text { consequences of SCRES }\end{array}$ & Survey & $\begin{array}{l}\text { Survey of } 391 \text { manufacturing firms of consumer packaged goods, } \\
\text { medical/ pharmaceuticals, industrial products, electronics, } \\
\text { appliances, automotive, apparel/ textile and aerospace. }\end{array}$ & Cross-sectional & USA \\
\hline Fakoor et al. (2013) & $\begin{array}{l}\text { SCRES through matching } \\
\text { capabilities with } \\
\text { vulnerabilities }\end{array}$ & Survey & Survey of 126 managers and experts in the automobile supply chain. & Cross-sectional & Iran \\
\hline $\begin{array}{l}\text { Golgeci \& } \\
\text { Ponomarov (2013) }\end{array}$ & $\begin{array}{l}\text { Firm innovativeness, } \\
\text { innovation magnitude } \\
\text { and SCRES }\end{array}$ & Survey & $\begin{array}{l}\text { Survey of } 121 \text { participants from the USA \& Europe with a response } \\
\text { rate of } 10.16 \% \text {. }\end{array}$ & Cross-sectional & $\begin{array}{l}\text { USA \& } \\
\text { Europe }\end{array}$ \\
\hline $\begin{array}{l}\text { Wieland \& } \\
\text { Wallenburg (2013) }\end{array}$ & $\begin{array}{l}\text { Relational competences } \\
\text { and SCRES }\end{array}$ & Survey & Survey of manufacturing firms with a response rate of $19.8 \%$. & Cross-sectional & $\begin{array}{l}\text { Germany, } \\
\text { Australia \& } \\
\text { Switzerland }\end{array}$ \\
\hline $\begin{array}{l}\text { Brandon-Jones et } \\
\text { al. (2014) }\end{array}$ & $\begin{array}{l}\text { Antecedents of SCRES } \\
\text { and robustness }\end{array}$ & Survey & Survey of 264 UK manufacturing plants, with a response rate of $22 \%$. & Cross-sectional & UK \\
\hline
\end{tabular}




\section{Table 6: Conceptual/Theoretical and Modelling Papers on SCRES}

\begin{tabular}{|c|c|}
\hline Conceptual and Theoretical Papers & Modelling Papers \\
\hline $\begin{array}{l}\text { Christopher \& Peck (2004); Christopher \& Rutherford (2004); Sheffi \& Rice } \\
\text { (2005); Sheffi (2005); Glickman \& White (2006); Tang (2006b) Kong \& Li (2008); } \\
\text { Xu (2008); Longo \& Oren (2008); Mascaritolo \&Holcomb (2008); Ponomarov \& } \\
\text { Holcomb (2009); Bhattacharya et al. (2009); Briano et al. (2009); Barroso et al. } \\
\text { (2010); Wedawatta et al. (2010); Boin et al. (2010); Briano et al. ( 2010); Erol et } \\
\text { al. (2010); Guoping \& Xinqiu (2010a); Guoping \& Xinqiu (2010b); Cabral et al. } \\
\text { (2011); Carvalho et al. (2011b); Barac et al. (2011); Cox et al. (2011); Vugrin et } \\
\text { al. (2011); Soni \& Jain (2011); Zhang et al. (2011); Carvalho et al. (2012a); } \\
\text { Carvalho et al. (2012c); Carvalho et al. (2012d); Bhattacharya et al. (2012); } \\
\text { Levesque (2012); Ponis \& Koronis (2012); Vlachos et al. (2012); Yao \& Meurier } \\
\text { (2012); Day (2014); Mensah \& Merkuryev (2014); Ivanov et al.(2014); Saenz \& } \\
\text { Revilla (2014) }\end{array}$ & $\begin{array}{l}\text { Allen et al. (2006); Lakovou et al. (2007); Datta et al. (2007); Ratick et al. } \\
\text { (2008); Falasca et al. (2008); Barksh \& Kleindorfer (2009); Jiang et al. (2009); } \\
\text { Mitra et al.(2009), Li \& Zhao (2010); Hu et al. (2010); Colicchia et al. (2010); } \\
\text { Yan \&Sun (2010); Yanfeng (2011); Murino et al. (2011); Zhao et al. (2011); } \\
\text { Carvalho et al. (2011a); Barroso et al. (2011); Shuai et al. (2011); Cabral et al. } \\
\text { (2012); Carvalho et al. (2012b); Chen \& Miller-Hooks (2012); Fang et al. } \\
\text { (2012); Ishfaq (2012); Klibi \& Martel (2012); Spiegler et al. (2012); Xiao et al. } \\
\text { (2012); Azevedo et al. (2013); Wang et al. (2013); Sawik (2013); Kristianto et } \\
\text { al. (2014); Adtiya, et al. (2014); Geng et al. (2014); Xu et al. (2014) }\end{array}$ \\
\hline Total $=39$ papers & Total $=33$ papers \\
\hline
\end{tabular}


Table 7: Summary of Theoretical Lenses Applied in Prior SCRES Research

\begin{tabular}{|l|l|}
\hline \multicolumn{1}{|c|}{ Theories } & \multicolumn{1}{c|}{ Authors } \\
\hline Resource Based View (RBV) & $\begin{array}{l}\text { Ponomarov \& Holcomb (2009); Blackhurst et al. (2011); } \\
\text { Park (2011); Ponomarov (2012); Yao \& Meurier (2012); } \\
\text { Brandon-Jones et al. (2014) }\end{array}$ \\
\hline Dynamic Capabilities & $\begin{array}{l}\text { Ponomarov \& Holcomb (2009); Ponomarov (2012); Yao } \\
\text { \& Meurier (2012); Golgeci \& Ponomarov (2013) }\end{array}$ \\
\hline Systems Theory & $\begin{array}{l}\text { Erol et al. (2010); Blackhurst et al. (2011); Spiegler et al. } \\
\text { (2012) }\end{array}$ \\
\hline Complex Systems & Allen et al. (2006); Erol et al. (2010) \\
\hline Complex Adaptive Systems & Day (2014) \\
\hline Contingency Theory & Park (2011); Brandon-Jones et al. (2014) \\
\hline $\begin{array}{l}\text { Resource Dependence, Strategic } \\
\text { Choice }\end{array}$ & Ponomarov (2012) \\
\hline Relational View & Wieland \& Wallenburg (2013) \\
\hline Social Capital & Johnson et al. (2013) \\
\hline Rational choice theory & Urciuoli et al. (2014) \\
\hline
\end{tabular}


Table 8: Comparison between the Features of a Complex Adaptive System (CAS), a Supply Chain and SCRES

\begin{tabular}{|c|c|c|c|}
\hline CAS Features & Description & Relevance to Supply Chains & Relevance to Supply Chain Resilience \\
\hline $\begin{array}{l}\text { Adaptation and Co- } \\
\text { evolution (Choi et al. } \\
\text { 2001; Schneider \& } \\
\text { Somers 2006; Pathak et } \\
\text { al.2007; Wycisk et al. } \\
\text { 2008; Day 2014). }\end{array}$ & $\begin{array}{l}\text { The CAS agents change so as to cope with changes } \\
\text { in other agents and its environment through self- } \\
\text { organisation. The CAS can also influence changes in } \\
\text { other agents as well as its environment. }\end{array}$ & $\begin{array}{l}\text { Due to environmental dynamism, the } \\
\text { supply chain changes in order to adapt. } \\
\text { The activities of individual firms may also } \\
\text { influence the supply chain environment. }\end{array}$ & $\begin{array}{l}\text { SCRES is an adaptive phenomenon } \\
\text { (Ponomarov \& Holcomb 2009; Hearnshaw \& } \\
\text { Wilson 2013; Adtiya et al. 2014). Firms adapt } \\
\text { to supply chain threats, but this may cause } \\
\text { more changes in the environment. }\end{array}$ \\
\hline $\begin{array}{l}\text { Multi scale/ } \\
\text { heterogeneous agents } \\
\text { (e.g. Choi et al. 2001; } \\
\text { Surana et al. 2005; } \\
\text { Wycisk et al. 2008) }\end{array}$ & $\begin{array}{l}\text { Agents refer to entities that form a CAS. They } \\
\text { operate at different levels in the system. Agents } \\
\text { may be individuals, teams, divisions or the entire } \\
\text { organization. They are heterogeneous for they } \\
\text { follow different schemas but aim to enhance their } \\
\text { fitness within the entire system. }\end{array}$ & $\begin{array}{l}\text { Agents in a supply chain may be the } \\
\text { individual firms. These operate at } \\
\text { different levels with different rules, } \\
\text { functions and objectives, e.g. supplier, } \\
\text { manufacturer, distributor, retailer and } \\
\text { customer. }\end{array}$ & $\begin{array}{l}\text { The resilience of a supply chain is a collective } \\
\text { outcome from the interactions of different } \\
\text { firms along the supply chain as they apply } \\
\text { schema (strategies and rules) to increase } \\
\text { fitness/survival (e.g. Day 2014). }\end{array}$ \\
\hline $\begin{array}{l}\text { Schema (Choi et al. } \\
\text { 2001; McCarthy 2003; } \\
\text { Surana et al. 2005; } \\
\text { Pathak et al. 2007; } \\
\text { Hasgall 2013) }\end{array}$ & $\begin{array}{l}\text { Schema refers to the norms, values, beliefs and } \\
\text { assumptions that are shared by a group of } \\
\text { individuals. It is a set of goal led rules that guide } \\
\text { the decisions and operations of individual CAS } \\
\text { agents. For example, schemas may include } \\
\text { strategies or plans in an organisation. }\end{array}$ & $\begin{array}{l}\text { Organisations within the supply chain } \\
\text { have rules, visions, objectives, goals and } \\
\text { strategies that guide their decisions and } \\
\text { operations. }\end{array}$ & $\begin{array}{l}\text { Schemas include strategies and plans } \\
\text { (McCarthy 2003) such as firms' supply chain } \\
\text { resilience strategies, which enable firms to } \\
\text { modify their operations and adapt to their } \\
\text { supply chain threats. }\end{array}$ \\
\hline $\begin{array}{l}\text { Environment, } \\
\text { Dynamism and rugged } \\
\text { landscape (Choi et al. } \\
\text { 2001; Pathak et al. } \\
\text { 2007) }\end{array}$ & $\begin{array}{l}\text { The environment in which the CAS operates } \\
\text { consists of other CASs and is more complex than } \\
\text { the CAS itself. The environment is rugged and } \\
\text { dynamic causing changes that the CAS agents must } \\
\text { adapt to in order to achieve fitness. This } \\
\text { adaptation may also cause changes in the whole } \\
\text { system as well as the environment. }\end{array}$ & $\begin{array}{l}\text { In a supply chain environment, changes } \\
\text { exist, e.g. in the supply base, statutory } \\
\text { regulations, etc. }\end{array}$ & $\begin{array}{l}\text { Environmental dynamism creates threats. } \\
\text { SCRES involves adaptation to both internal } \\
\text { and external threats. }\end{array}$ \\
\hline $\begin{array}{l}\text { Ability to learn (Wycisk } \\
\text { et al. 2008; Day 2014) }\end{array}$ & $\begin{array}{l}\text { Agents in a CAS learn by obtaining information } \\
\text { from their relationships within the system and the } \\
\text { surrounding environment. It is through their } \\
\text { dynamic learning that they are able to make } \\
\text { decisions on modifying their capabilities and }\end{array}$ & $\begin{array}{l}\text { Organizational learning exists among } \\
\text { firms/agents in the supply chain. }\end{array}$ & $\begin{array}{l}\text { Organisational learning enhances SCRES } \\
\text { (Ponomarov \& Holcomb 2009; Pettit 2010; } \\
\text { Ponis \& Koronis 2012). Learning helps in } \\
\text { adaptation by facilitating the modification of } \\
\text { resilience strategies. }\end{array}$ \\
\hline
\end{tabular}




\begin{tabular}{|c|c|c|c|}
\hline & $\begin{array}{l}\text { changing their schema in order to improve their } \\
\text { fitness and performance. }\end{array}$ & & \\
\hline $\begin{array}{l}\text { Nonlinearity (Choi et al. } \\
\text { 2001; Urry 2005; Surana } \\
\text { et al. 2005; Brownlee } \\
\text { 2007; Pathak et al. } \\
\text { 2007; Wycisk et al. 2008; } \\
\text { Day 2014). }\end{array}$ & $\begin{array}{l}\text { There is a non-linear relationship between the } \\
\text { cause and effect of CAS events. For example, a } \\
\text { seemingly small event may cause extremely large } \\
\text { effects in the system (either positive or negative). } \\
\text { Similarly, severe events may yield very trivial } \\
\text { effects and at times no effect at all. }\end{array}$ & $\begin{array}{l}\text { A small change in the downstream part of } \\
\text { the supply chain can cause amplified and } \\
\text { oscillating changes in the supply chain } \\
\text { upstream, e .g. the bullwhip effect. }\end{array}$ & $\begin{array}{l}\text { Due to non-linearity coupled with } \\
\text { interdependence, seemingly small } \\
\text { disturbances can result in massive supply } \\
\text { chain threats. Survival depends on } \\
\text { embracing SCRES strategies, such as } \\
\text { increasing visibility and flexibility through } \\
\text { multiple-sourcing (Hopkins 2005). }\end{array}$ \\
\hline $\begin{array}{l}\text { Network connectivity/ } \\
\text { interaction( Choi et al. } \\
\text { 2001; Pathak et al. } \\
\text { 2007; Wycisk et al. } \\
\text { 2008) }\end{array}$ & $\begin{array}{l}\text { A CAS is composed of agents and their } \\
\text { connections. The connectivity of these agents } \\
\text { determines the complexity and the dimensionality } \\
\text { of the CAS. }\end{array}$ & $\begin{array}{l}\text { Agents in a supply network have physical } \\
\text { connection that facilitates the flow of } \\
\text { information, resources and materials. } \\
\text { Such connections include telephone lines } \\
\text { and the internet. }\end{array}$ & $\begin{array}{l}\text { Supply network connectivity and clustering } \\
\text { facilitated by information flows facilitate } \\
\text { collaboration, reduce opportunistic } \\
\text { behaviour and enhance resilience } \\
\text { (Hearnshaw \& Wilson 2013). }\end{array}$ \\
\hline $\begin{array}{l}\text { Dimensionality (Choi et } \\
\text { al. 2001; Surana et al. } \\
\text { 2005) }\end{array}$ & $\begin{array}{l}\text { Dimensionality refers to the degree of freedom an } \\
\text { individual agent possesses in order to act } \\
\text { somehow autonomously. }\end{array}$ & $\begin{array}{l}\text { Supply chain entities have different } \\
\text { objectives and constraints. They operate } \\
\text { autonomously although their connectivity } \\
\text { with other supply chain members causes } \\
\text { some interdependence. }\end{array}$ & $\begin{array}{l}\text { Individual firms have partial freedom to } \\
\text { make decisions. This contributes to self- } \\
\text { organisation, emergence and adaptation } \\
\text { (e.g. McCarthy et al. 2006), which are crucial } \\
\text { for SCRES. }\end{array}$ \\
\hline $\begin{array}{l}\text { Self- Organization and } \\
\text { emergence (Choi et al. } \\
\text { 2001; Surana et al. } \\
\text { 2005; Schneider \& } \\
\text { Somers 2006; Brownlee } \\
\text { 2007; Pathak et al. } \\
\text { 2007; Wycisk et al. } \\
\text { 2008; Nilsson \& } \\
\text { Gammelgaard 2012) }\end{array}$ & $\begin{array}{l}\text { Decisions made by individual agents cause new } \\
\text { structures, patterns and properties to emerge at } \\
\text { the system level without being externally } \\
\text { controlled or imposed by any single agent. Some } \\
\text { agents may have greater influence on the system } \\
\text { than others, but they cannot control it entirely. }\end{array}$ & $\begin{array}{l}\text { There is no single firm that deliberately } \\
\text { controls or organises the entire supply } \\
\text { chain. It simply emerges in part because a } \\
\text { firm cannot manage the entire extended } \\
\text { supply chain. Each firm tries to achieve its } \\
\text { goals but this in turn contributes to the } \\
\text { collective behaviour of the entire } \\
\text { network. }\end{array}$ & $\begin{array}{l}\text { Resilience is an emergent feature of a supply } \\
\text { chain (Day 2014; Golgeci \& Ponomarov } \\
\text { 2013). It is a result of self- organised } \\
\text { processes that enhance adaptation (Palin } \\
\text { 2013). No single firm controls the resilience } \\
\text { of the entire supply chain (Geng et al. 2014). }\end{array}$ \\
\hline $\begin{array}{l}\text { Scalability (e.g. Surana } \\
\text { et al. 2005; Wycisk et al. } \\
\text { 2008) }\end{array}$ & $\begin{array}{l}\text { The same causal dynamics in a CAS may apply } \\
\text { across all of its levels. }\end{array}$ & $\begin{array}{l}\text { Agents/ firms at different tiers in the } \\
\text { supply chain may have similar concerns, } \\
\text { e.g. improving quality, delivery speed and } \\
\text { reducing cost. }\end{array}$ & $\begin{array}{l}\text { Inter-relatedness within a supply chain and } \\
\text { the presence of common schema shared by } \\
\text { firms are vital for the adaptation and survival } \\
\text { (resilience) of the entire supply chain (e.g. } \\
\text { Schneider \& Somers 2006). }\end{array}$ \\
\hline
\end{tabular}


